\title{
Wave slam on wave piercing catamarans in random head seas
}

M.R.Davis ${ }^{1}$, B.J.French ${ }^{2}$ and G.A.Thomas ${ }^{3}$

1 School of Engineering and ICT, University of Tasmania (corresponding author)

2 dorsaVi, Melbourne, Australia.

\section{Department of Mechanical Engineering, University College, London}

\begin{abstract}
Tests on a hydro-elastic $2.5 \mathrm{~m}$ model in random seas showed wave impacts to be close to the aft end of the short center bow at intervals of over 3 encountered modal wave periods, with longer intervals in smaller seas and for shorter modal periods. Slams were only detected in wave heights exceeding $1.5 \mathrm{~m}$ at full scale. Slam loads in $4 \mathrm{~m}$ seas were mostly about $25 \%$ of the hull weight but some reached $132 \%$ of the hull weight. Slam durations were generally about 0.35 seconds at full scale. Slam induced bending was found to reach $11 \%$ of the product of hull weight and length. Simulation of slamming within a time domain seakeeping computation showed slightly higher median relative velocities at the slam instant than was observed in the model tests.
\end{abstract}

\section{Introduction}

This investigation aims to identify the random sea slamming behaviour of the INCAT Tasmania Wave Piercing Catamaran (WPC) design. This incorporates a short central bow with substantial reserve buoyancy above the waterline in the bow area (INCAT Tasmania, 2016). The approach here is to investigate the slamming by towing tank tests in random waves and thus to establish a data base representing the observed slam events. Slam occurrence and loadings are then related to the kinematics of the ship motion and an empirical algorithm is developed for occurrence and severity of slamming for incorporation into a time domain sea keeping program (Holloway and Davis, 2006).

High speed catamaran ferries operate at length Froude numbers in excess of 0.5 and so experience heave and pitch motions in excess of the wave height and wave slope (Davis et al., 
2005). These large motions expose vessels to wave impact in the bow region. Deck diving in following seas can be hazardous (Lavroff et al., 2010) and the WPC design virtually eliminates deck diving and green water over the bow by virtue of the short centre bow. The configuration is inherently nonlinear since the keel of the central bow is close to the water line and thus has little effect on the motion in small or moderate seas but in large seas can generate large upward forces when immersed in large waves. When the arched cross section between main hulls and the central bow fills with water large slam forces can arise due to the confluence of displaced water at the top of the arches. Slam induced bending loads thus become critical design loads (Lavroff et al., 2011). Whilst it is possible to simultaneously compute the transient hydrodynamic and structural response problems (McVicar et al., 2014) this involves computing times for random seas which can be as much as $10^{5}$ times real time per CPU (McVicar et al., 2014) owing to the long period of wave encounter relative to short duration slams (McVicar et al., 2015). Using the Green Function, time domain method (Holloway and Davis, 2002) this is reduced to approximately 10 minutes of CPU time per minute of real time. Therefore we aim here to develop empirical relations for slamming to be applied in time domain high speed strip theory (Davis and Holloway, 2003) to investigate the statistics of slamming in random seas within a practicable overall time frame of computation (French et al., 2010, 2012). Since slam events do not have a dominant effect on hull motions, any one slam event has little effect on the prediction of subsequent slam events after a number of subsequent wave encounters. Hydroelastic effects, which are important owing to the similar time scales of slam duration and hull whipping period (Lavroff et al., 2007, 2009), are effectively incorporated by the use of the empirical algorithm emanating from the hydroelastic tank test data.

In the random sea tests to be reported here a segmented model originally tested in regular waves (Lavroff et al., 2007) has been used. The model design follows broadly similar techniques to those of McTaggart et al. (1997), Hermundstad et al. (2007), Dessi et al. (2003, 2007) and Okland et al. (2003). The hull segments are attached to backbone beams which incorporate flexible links at the 
segment joins. A model with three segments is sufficient in the present testing as higher order modes are not expected to have a significant effect (McVicar et al., 2015).

Computation of the unsteady hydrodynamic response here uses the time domain, high speed strip (or 2.5D) theory (Holloway and Davis, 2002) based on the two dimensional transient Green function (Davis and Holloway, 2003) formulated in a spatially fixed reference frame. This method has been developed for random seas (French et al., 2010, 2012) and gives good motion predictions for length based Froude numbers above 0.3. This method predicts the long term motion response in a random seaway and thus predicts when slams occur and the slam severity. The developed code is applied here to the prediction of slamming for a 112m INCAT Tasmania built WPC operating under representative head sea conditions.

\section{Towing tanks tests of the hydroelastic model in random head seas}

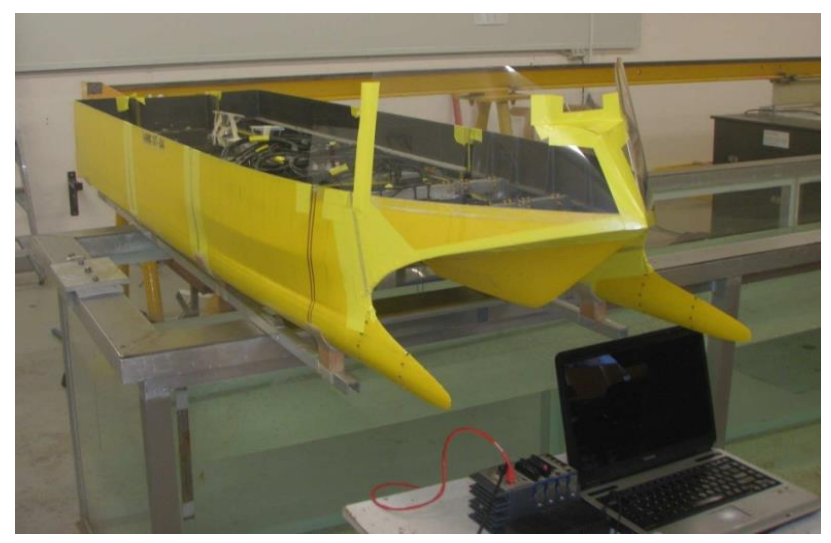

Figure 1: The $2.5 \mathrm{~m}$ hydroelastic segmented model of the $112 \mathrm{~m}$ INCAT Tasmania WPC. The cRIO DAQ system can be seen at the bottom of the photo next to the personal computer

Figure 1 shows the $2.5 \mathrm{~m}, 27 \mathrm{~kg}$ model used in the tank testing and figure 2 shows a schematic layout of the model. The model has segments connected by flexible links (Lavroff et al., 2009): a rigid central section with aft wet deck attached and port and starboard forward and aft demihull sections. The bow is mounted on transverse beams, pin jointed at the demihull connections and each with flexible links approximately mid-way between the overall centre line and the demihulls. All eight flexible links are short rectangular aluminium sections machined with larger plugs which bolt rigidly into the hollow beams forming the backbones of the demi-hulls and 
the transverse bow mounting beams. The flexible links tune the main model vibratory modes to appropriate frequency and facilitate measurement of dynamic bending loads by strain gauges mounted on the upper and lower surfaces of each link. Thus dynamic vertical bending moments (VBMs) in the main demi-hulls can be recorded and the vertical load on the bow and its location determined. The main longitudinal whipping mode of the model is tuned to a frequency of $13.8 \mathrm{~Hz}$ to simulate full scale whipping at approximately $2.4 \mathrm{~Hz}$ (Lavroff et al., 2009). The bow of the model was fitted with an array of pressure tappings for Endevco fast response strain gauge pressure transducers. Figure 2 shows the location of these pressure tappings along the top of the starboard arched cross sections.

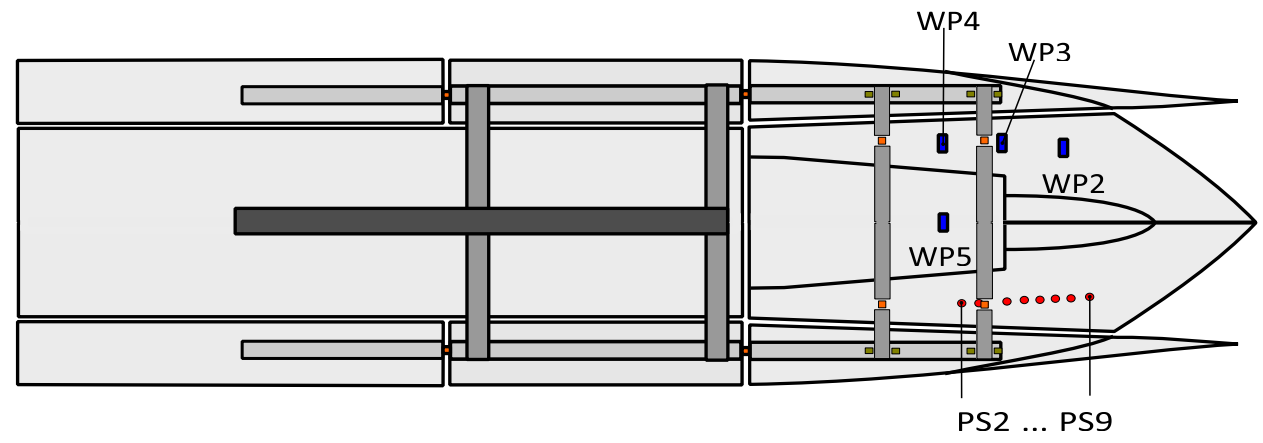

Figure 2: Structural arrangement of the $2.5 \mathrm{~m}$ segmented catamaran model showing discrete model segments, elastic connecting links between segments, wave probe (WP) and pressure transducer (PS) locations (only the arch top locations are shown here).
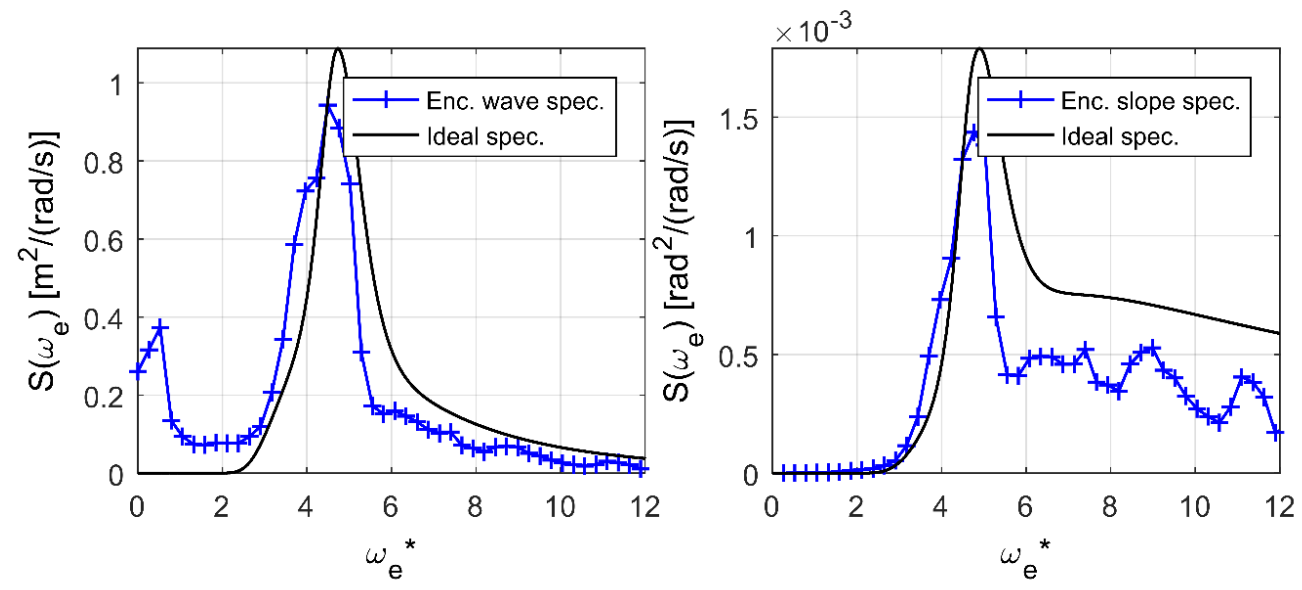

Figure 3: Encountered wave elevation and slope spectra for $\mathrm{H} 1 / 3=78.1 \mathrm{~mm} \mathrm{T0}=1.5 \mathrm{~s}, \mathrm{U}=$ 
The model was tested in random waves in the $100 \mathrm{~m}$ towing tank at the Australian Maritime

College of the University of Tasmania. A paddle wave maker generated a JONSWAP wave spectrum of the required significant wave height and wave period in 500 component bands (French et al., 2015). Figure 3 compares the spectrum achieved by the wavemaker with the ideal JONSWAP spectrum. It is noted that the spectra are of relatively narrow bandwidth.

The testing time recommended by Lloyd (1989) was found to require approximately eight runs along the tank at each condition. Table 1 lists the test conditions used for the model tests and the number of slams observed at each condition: there were between 66 and 171 slams at each condition and a total of 1812 slams observed over 18 test conditions.

\begin{tabular}{|c|c|c|c|c|}
\hline \multirow{2}{*}{$\begin{array}{c}\text { Modal wave } \\
\text { period }(\mathrm{s})\end{array}$} & \multirow{2}{*}{$\begin{array}{c}\text { Model speed } \\
(\mathrm{m} / \mathrm{s})\end{array}$} & \multirow{2}{*}{$\begin{array}{c}\text { Model Froude } \\
\text { Number }\end{array}$} & & \multicolumn{2}{|c|}{ Number of slams recorded } \\
\cline { 4 - 5 } & & 0.311 & $78 \mathrm{~mm}$ & $89 \mathrm{~mm}$ \\
\hline 1.5 & 1.54 & 0.434 & 110 & 100 \\
\hline 1.5 & 2.15 & 0.311 & 131 & 171 \\
\hline 1.3 & 1.54 & 0.590 & 90 & 66 \\
\hline 1.5 & 2.92 & 0.434 & 132 & 137 \\
\hline 1.3 & 2.15 & 0.590 & 98 & 86 \\
\hline 1.3 & 2.92 & 0.311 & 97 & 83 \\
\hline 1 & 1.54 & 0.434 & 101 & 106 \\
\hline 1 & 2.15 & 0.590 & 83 & 58 \\
\hline 1 & 2.92 & & & \\
\hline
\end{tabular}

Table 1: Model test conditions

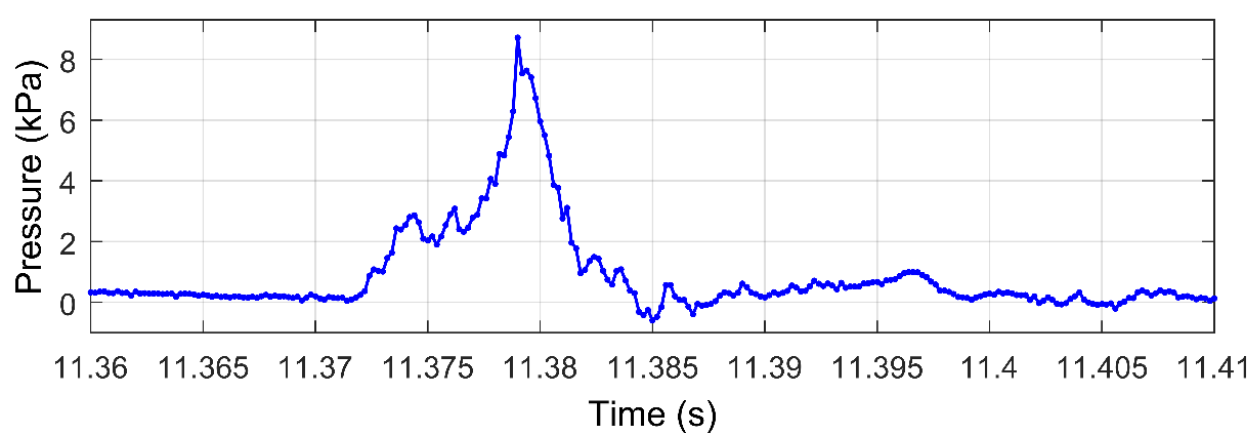

Figure 4: Pressure time trace for a typical slam event in an irregular sea. DAQ sample rate 5kHz. Note that the duration of the entire surface pressure event is no more than $0.015 \mathrm{~s}$.

Slams were identified using the pressure transducers located at the top of the arch between the demihulls and centre bow (Figure 2). These transducers only recorded pressure transients when 
the water surface impacted at the arch top. Figure 4 shows a typical transient pressure record sampled at $5 \mathrm{KHz}$ to resolve the pressure transients clearly. The pressure transducer located close to the aft end of the centre bow was used as the reference for the purpose of slam identification. Signal records were inspected manually to eliminate spurious small noise components being identified as slams. As can be seen in Figure 4 the pressure peak generated by a typical slam was of approximate duration 0.01 second. The peak shown in figure 4 would correspond to a panel pressure of approximately $380 \mathrm{kPa}$ at full scale.

Figure 5 shows the median peak slam pressure distribution along the length of the hull as a function of normalized encounter angular frequency. Ship frames are spaced at $1.2 \mathrm{~m}$ at full scale or $2.68 \mathrm{~cm}$ at model scale, the centre bow truncation being at frame 71 from the demi-hull aft transoms of the vessel. The dimensionless angular wave encounter angular frequency $\left(\omega_{0 e}^{*}=\right.$ $\left.2 \pi f_{0 e} \sqrt{L / g}\right)$ is normalized by the hull length $(L)$ and acceleration due to gravity $(g)$ and the mean encounter frequency $\left(f_{0 e}\right)$ corresponds to the encountered period of a modal period wave $\left(T_{0 e}\right.$, where $f_{0 e}=1 / T_{0 e} \mathrm{~Hz}$ ). For low encounter frequencies there is an extended regions of high impact pressure with peak median pressures of about $5 \mathrm{kPa}$ ahead of and aft of the centre bow truncation. Slam pressures are reduced significantly to a peak median pressure of about $3 \mathrm{kPa}$ close to the centre bow truncation for a narrow range of modal wave period or equivalent encounter frequency, and then increase to a maximum of about $6 \mathrm{kPa}$ somewhat aft of the centre bow truncation. Individual slams may produce peak pressures well in excess of the median values as will be described later where the maximum slam peak total force exceeds the median by as much as 5.5 times. In regular wave testing (Davis and Holloway, 2003; Lavroff and Davis, 2016) maximum motions occur at $\omega_{e}^{*} \simeq 5$ and the occurrence of maximum median slam pressures at close to that encounter frequency is expected if slamming is primarily due to hull motions. Also, there are significant changes of phase between encountered wave, heave and pitch motions for dimensionless encounter frequencies between 4 and 5 which give rise to the relatively rapid 
variation of median slam pressure and its location observed in figure 4. Small values of the median maximum slam pressure are due to small relative motions of the bow to the wave surface when the phasing is such that upward heave and bow down pitch are in phase over that narrow band of encounter frequency.



Figure 5: Median pressure distribution at the arch top for the $78.1 \mathrm{~mm}$ (full scale $3.5 \mathrm{~m}$ ) significant wave height conditions as a function of lengthwise location and dimensionless wave encounter angular frequency $\omega_{0 e}^{*}$. The centre bow truncation is located at frame 71 , full scale frame spacing is $1.2 \mathrm{~m}$. Point markers identify the locations of the pressure transducers Corrections to allow for bow segment structure inertia loads were applied to the measured upward forces with reference to the measured hull motion accelerations as recorded by the two tow post LVDTs as verified previously (French et al., 2014). Figure 6 shows a typical time record for the external upward slam load. There are two distinct components in Figure 6(a): a relatively slowly varying global load and a much more rapidly time varying slam loading. Signal filtering was applied to remove the global loading component to yield the slam component shown in Figure 6(b). The bow experiences a global loading component as it moves through the encountered wave surface without the filling of the arches. The slam event involves both upward and downward loads 

in contact with the water.

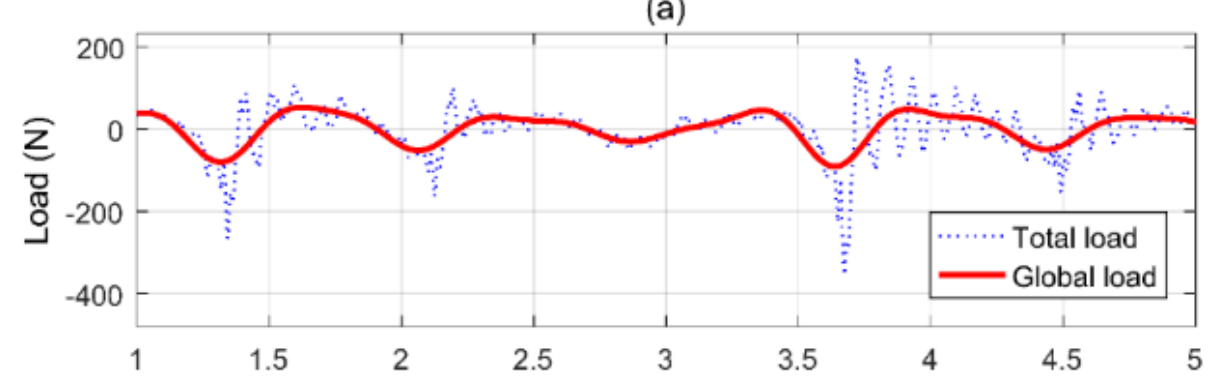

(b)

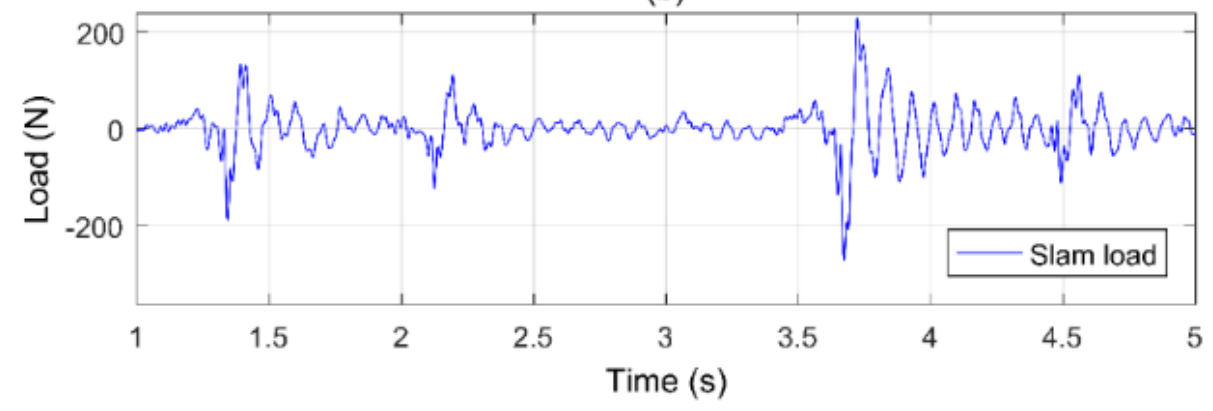

due to whipping vibration at $13.8 \mathrm{~Hz}$ of the hull which decays with time as the bow vibrates whilst

(a)$$
\text { . }
$$ 
at wave periods which give rise to maximum hull motions. At higher or lower wave periods the motions are smaller and slams occur at about 6-9 modal period intervals. As the wave height is reduced slams occur less frequently at intervals of 10 or more modal wave periods. These results form the basis for procedures for identification of conditions for a slam to occur in the time domain ship motion computation.
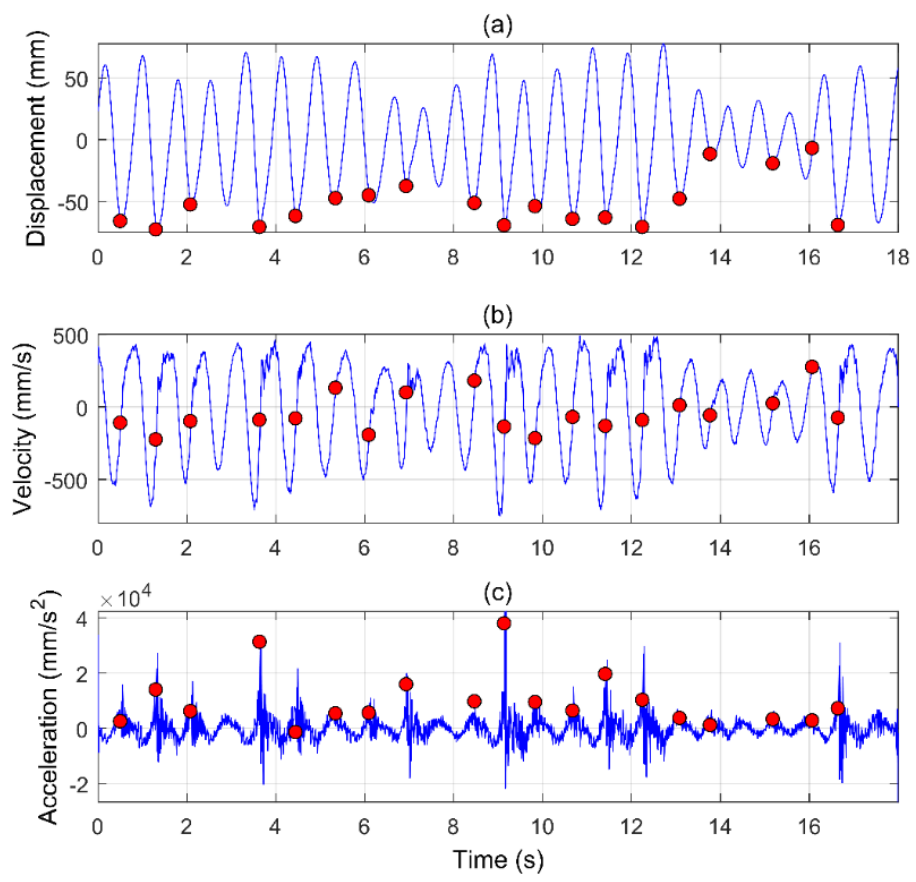

Figure 7: (a) Centre bow truncation absolute vertical displacement (with reference to calm water). (b) Vertical velocity. (c) Vertical acceleration calculated from the LVDT signals. Identified slam events are shown by markers. Modal wave period $T_{0}=1.5 \mathrm{~s}, H_{1 / 3}=78.1 \mathrm{~mm}, U=2.15 \mathrm{~m} / \mathrm{s}$.

Figure 9 shows the variation of slam peak load with forward speed, wave height and modal wave period, expressed as a percentage of vessel gross weight. The modal wave period is normalized with reference to vessel speed and length. The median, lower and upper quartile loads are shown as also is the most extreme large slam observed during the tank tests. The largest observed slam greatly exceed the upper quartile values by a factor of up to 3.3. This shows that there will be appreciable uncertainty in design to withstand the most severe slam as very long test durations would be required to observe a sufficient number of large slams that the probability of occurrence of large slams could be reasonably determined. Moreover, the application of a standard probability 
distribution to the test data would not be appropriate for extreme low probability events as it would seem that there would necessarily be a finite physical limit to the magnitude of slamming load. However, the results obtained here show that very high slam peak loads can occur, the largest slam observed being 1.32 times the hull weight. The identification of slams and analysis of the loading signals to determine the peak load in each slam event have been explained by French et al. (2014).

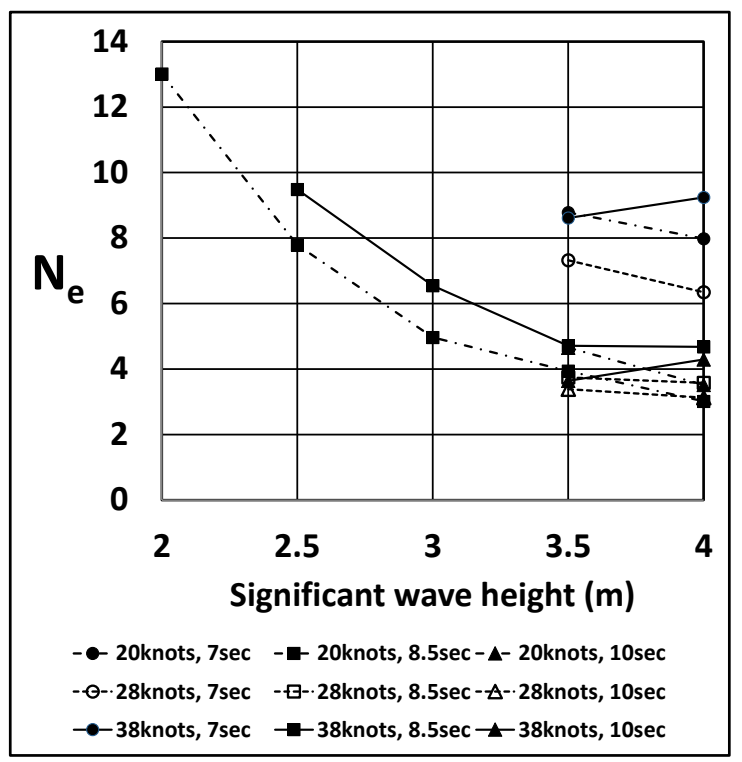

Figure 8: Number of encountered modal period waves per slam $\left(\mathbf{N}_{\mathbf{e}}\right)$ for various combinations of wave height, modal period and forward speed. Model data scaled to full size $112 \mathrm{~m}$ vessel.
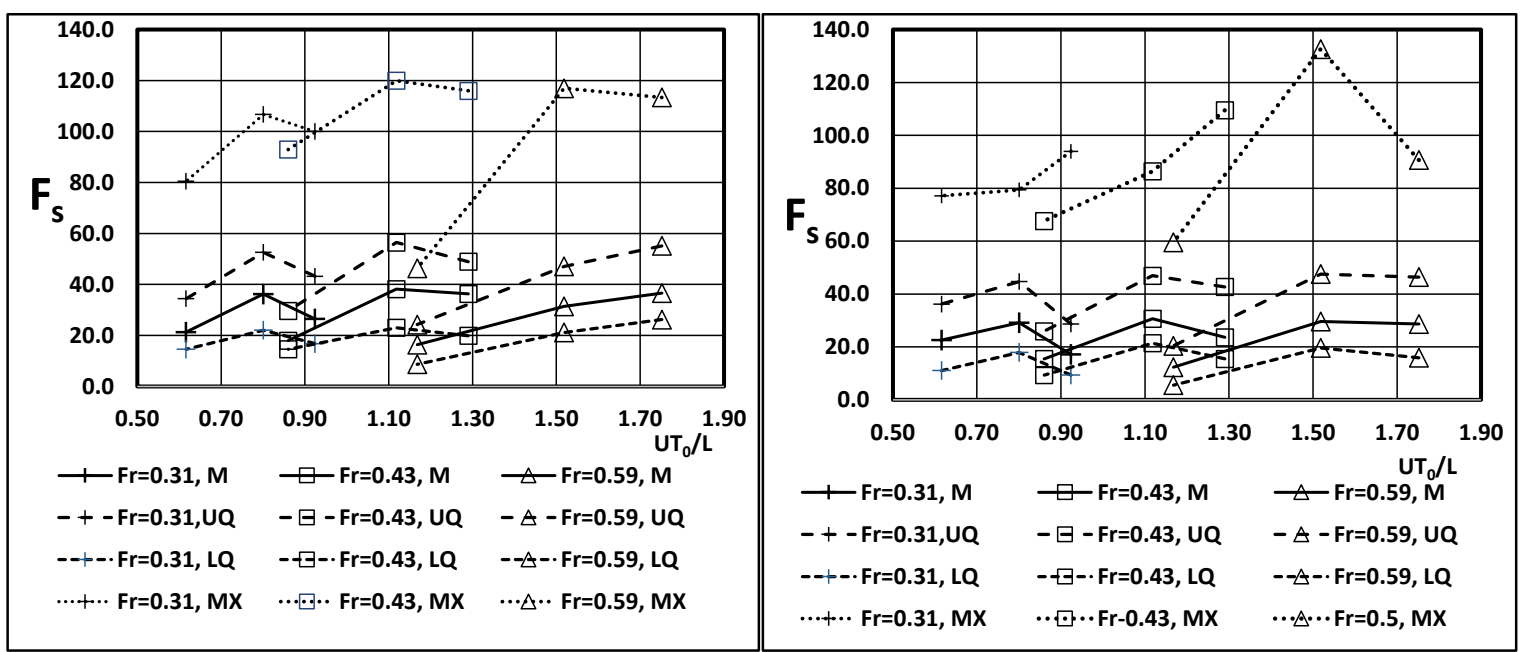

Figure 9: Peak slam forces $\left(\mathbf{F}_{\mathbf{s}}\right)$ as a percentage of vessel weight and as a function of normalized modal wave period and vessel Froude number (Median (M), upper quartile (UQ), lower (LQ) quartile and maximum observed (MX)). Significant wave height: left - $89 \mathrm{~mm}$ and right - $78 \mathrm{~mm}$. 
Whilst the peak slam loads are high there is a very rapid rise of loading when the slam occurs and the duration of slam loading is quite short. Thus the overall impulse imposed by the slam on the hull structure does not have a substantial effect on the subsequent motions of the hull other than the excitation of whipping vibration which decays rapidly due to damping (Lavroff al., 2013).

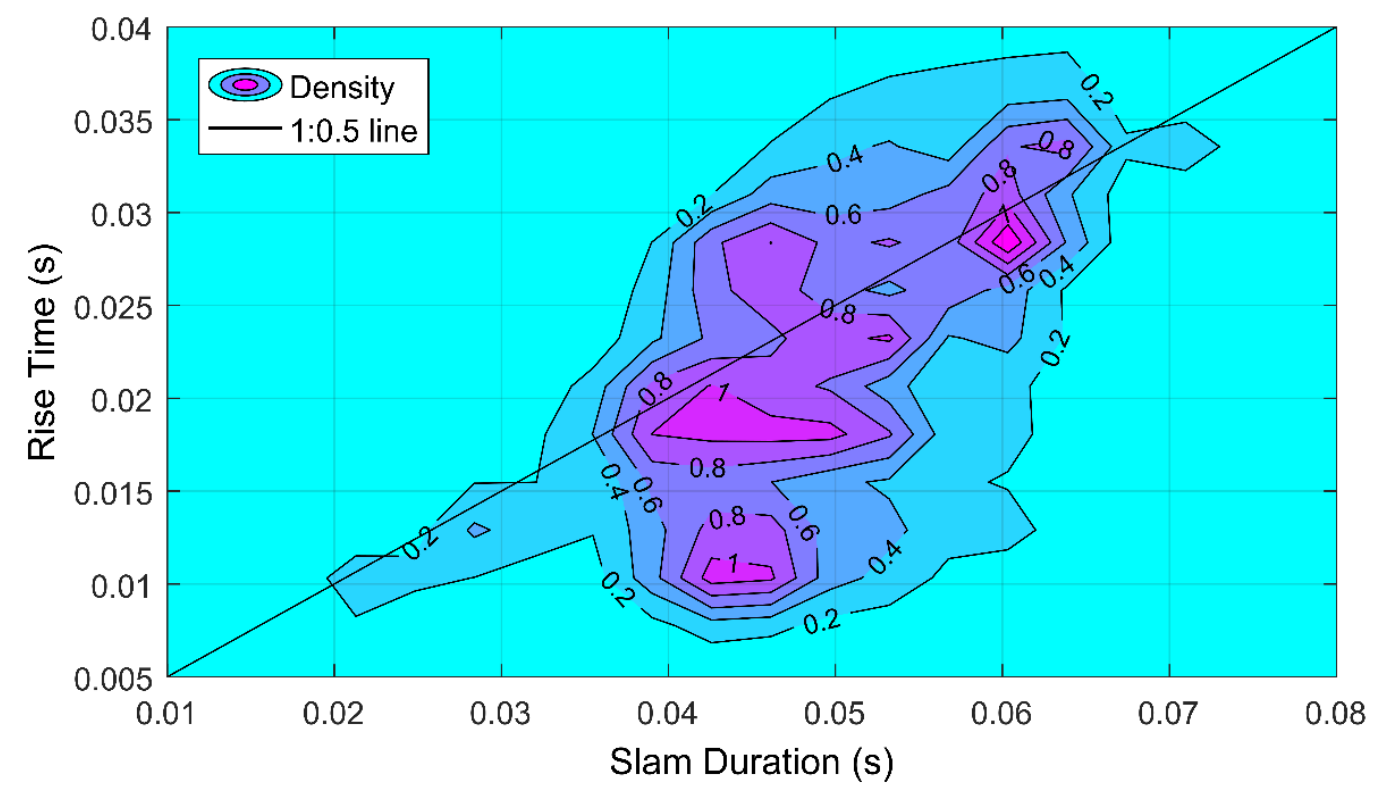

Figure 10: Variation of slam rise time and slam duration observed in the model tests. Contours show the maximum slam loads normalized to the maximum observed slam load.

Figure 10 shows a normalized distribution for all observed slams in terms of the duration of the slam and the rise time of the slam at model scale. The duration of a slam is here defined as the time between commencement of the main upward load on the bow and the time at which the load reduces to zero following the upward peak of load. We see that most model test slams have a duration of between 40 and 65 milliseconds and a rise time between 10 and 35 milliseconds. At full scale this would correspond to durations between 0.27 and 0.44 seconds and rise times between 0.067 and 0.23 seconds. The period of whipping of the model hull is approximately 70 milliseconds and so it is evident that slams have a rise time and overall duration which are both less than, but not very much less than, the whipping period. For this reason we see that it is important that whipping motion is properly replicated in the hydroelastic test model if the transient slam loading is to be correctly modelled as the slam impulsive loading in the bow area is 
transmitted into whipping vibration of the entire hull. Slams appear to occur in two groups with regard to duration and the short duration group is further divided into two groups of larger and smaller rise time. These features are a consequence of the transient hydrodynamics of the filling of the arches between the hulls which has been shown on the basis of CFD solutions for slam events (McVicar et al., 2015).
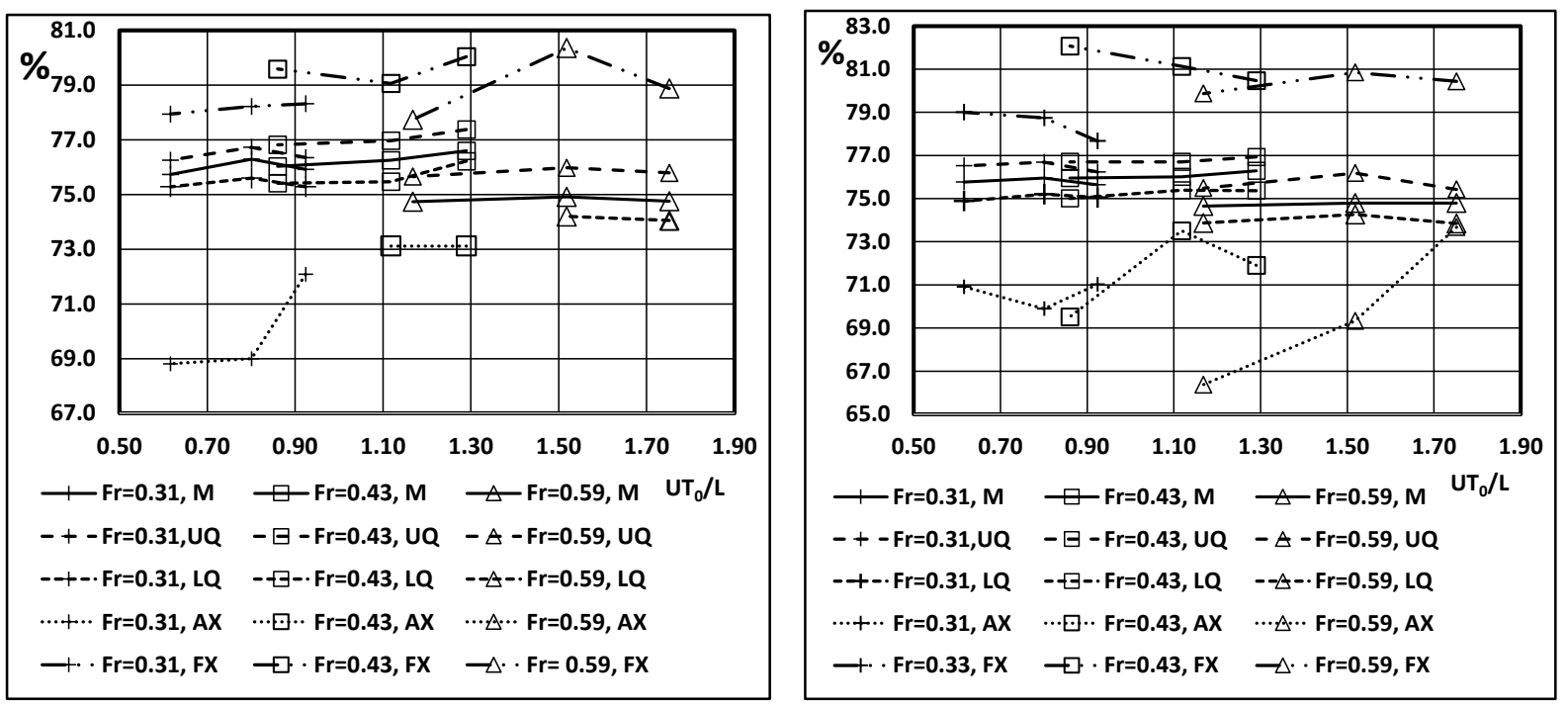

Figure 11: Slam location as percentage of hull length from transom (Median (M), upper quartile (UQ), lower (LQ) quartile, maximum aft observed (AX) and maximum forward observed (FX); centre bow truncation is at $76.1 \%$ of length from transom. Significant wave height: left - $89 \mathrm{~mm}$ and right - 78mm).

The location of the resultant slam loading is shown in Figure 11 in terms of the percentage of in regular wave conditions (Lavroff et al., 2009, 2013; Lavroff and Davis, 2015). Whilst a few slams are located significantly outside the quartile range, many of those were rather small slams hull length. The median position of resultant slam load is close to the centre bow truncation at the lower speeds but moves about $1.5 \%$ of hull length aft at the highest test speed. Upper and lower quartiles are general within about $1 \%$ of the median position. Occasionally slams occur outside this rather narrow range of locations. This outcome is generally consistent with previous findings for which the identification of location inevitably becomes less precise. 


\begin{tabular}{|l|c|c|c|c|}
\hline & LowQ & Median & UpperQ & Max \\
\hline Slam force* & $15 \%$ & $25 \%$ & $40 \%$ & $132 \%$ \\
\hline FWDSag ** & $1.0 \%$ & $2.5 \%$ & $5.2 \%$ & $11.4 \%$ \\
\hline FWDHog** & $1.6 \%$ & $2.8 \%$ & $4.7 \%$ & $9.1 \%$ \\
\hline AFTSag** & $0.7 \%$ & $1.5 \%$ & $2.5 \%$ & $5.1 \%$ \\
\hline AFTHog** & $1.9 \%$ & $3.2 \%$ & $5.0 \%$ & $9.8 \%$ \\
\hline
\end{tabular}

Table 2: Peak measured slam forces and vertical bending moments in sag and hog at forward and aft segment links over all conditions (median, upper and lower quartile and maximum observed values). * - percentage of hull weight; **- percentage of hull weight x overall hull length.

An important aspect of slamming is the bending that it applies to the hulls which was measured at the two joins between the demi-hull segments at $42.8 \%$ and $19.6 \%$ of overall length aft of the centre bow truncation. Table 2 summarizes the peak bending loads in sag and in hog for all the observed slam events before commencement of the subsequent whipping vibration. The bending loads at the more forward location have a median of $2.5 \%$ of the product of hull weight and length in sag and $2.8 \%$ in hog. The largest observed bending moment was $11.4 \%$ of the product of hull weight and length in sag at the forward section. At the aft position the induced bending is generally similar but greater in hog than in sag. This is a consequence of the transient transmission of the slam load into whipping vibration of the complete hull as discussed above. Extreme values are approximately twice the upper quartile slam induced bending moment. The sag values represent the first upward bending due to the slam and the hog values are the first opposite moment following that. The fact that the hog values are so large emphasizes the importance of simulating the dynamics of the response to wave impact using a hydro-elastic model since it is clear that the initial slam event has a timescale similar to the whipping period so that the application of the external hydrodynamic slam load and initiation of the whipping response take place simultaneously. That is, the slam cannot be regarded simply as a delta function excitation of the whipping vibration.

Figure 12 shows the relationship between maximum slam load and the maximum slam induced vertical bending moment scaled to full scale at the location of the forward model segment join. 
We see that there is a relatively well defined proportionality. Bearing in mind that slams mostly occur close to the centre bow truncation this suggests that we can simply define a slam moment in terms of an effective length which can be determined from the slope of the trend line through the data in Figure 12. This length is $14.9 \mathrm{~m}$ at full scale whereas the physical distance between the CBT and the location of the forward links is $21.8 \mathrm{~m}$. Thus the observed demi hull maximum slam induced moments are $68 \%$ of the product of the maximum slam force and its distance to the demihull section where the links are located. This also underlines the significant effect of dynamic structural transients in the bending response to slam loading which act to reduce the hull sag bending moments compared to the simple product of slam force and distance to the location of the slam load. However, it appears from the trend shown in Figure 12 that the slam load magnitude can be used in estimating vertical bending moments at the forward section of the hull provided that the physical separation is appropriately reduced in the calculation and that consideration is given to variability. The maximum sag bending loads at the aft segment join were very much smaller and such a simplified approach would not be appropriate at that location.

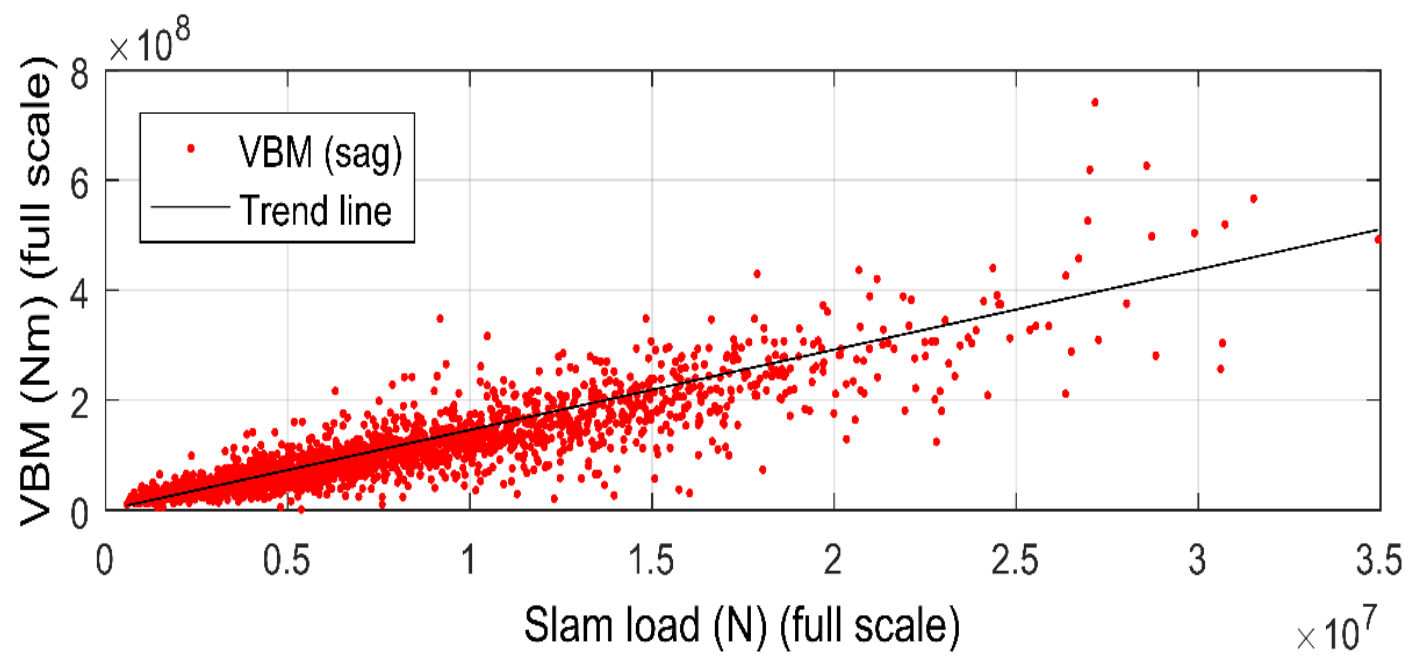

Figure 12: Experimentally measured vertical bending moment at the forward links (equivalent to $63.4 \mathrm{~m}$ from the transom at full scale) scaled to full scale as a function of centre bow slam load. A linear least-squares fit trend line is shown. 

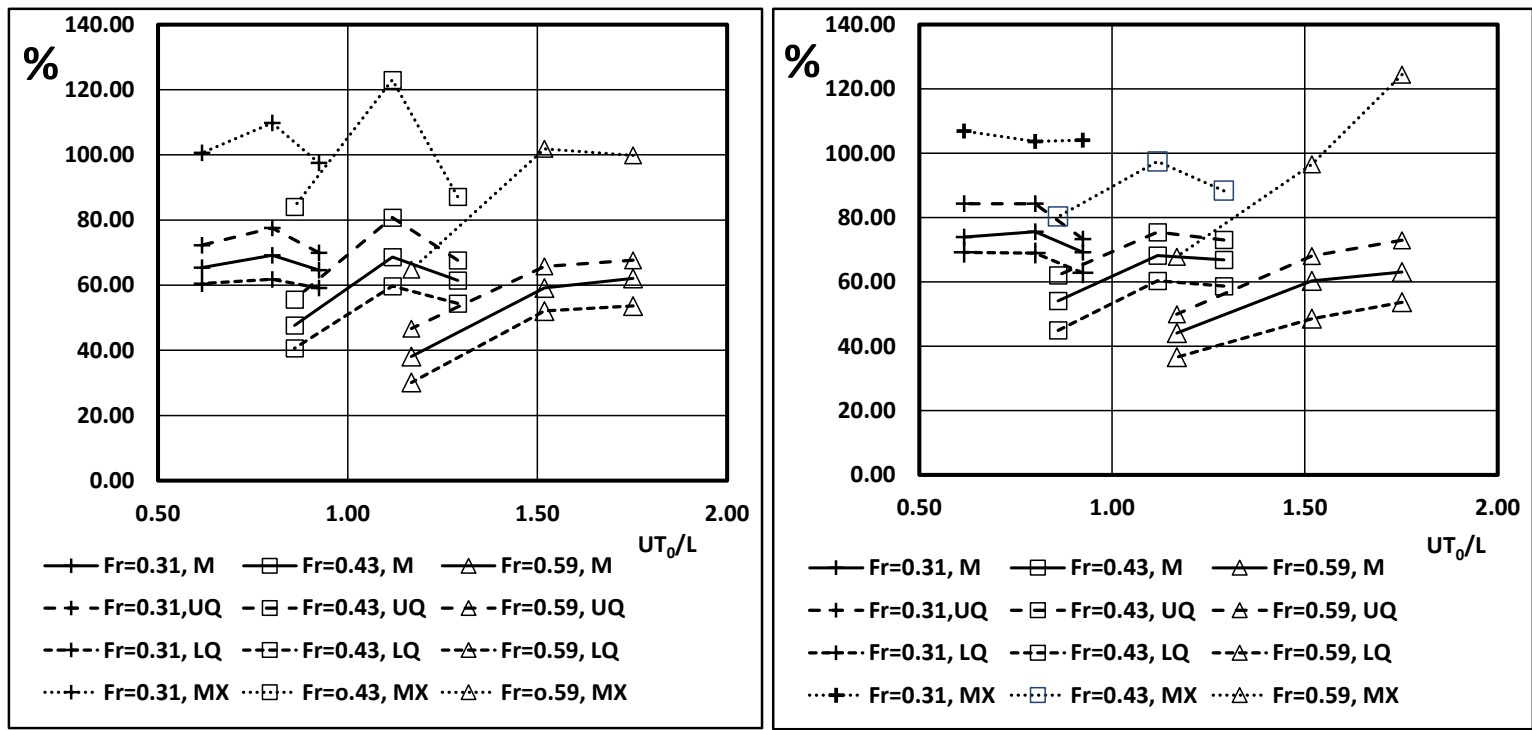

Figure 13: Peak model bow displacement relative to the undisturbed wave surface during slam

events as percentage of significant wave height and as a function of normalized modal wave period and Froude number (Median (M), upper quartile (UQ) and lower (LQ) quartile and maximum (MX). Significant wave height: left- $89 \mathrm{~mm}$ and right - 78mm)

In order to establish a basis for embedding a slam prediction capability within a global motion computation it is necessary to consider data relating to the kinematics of the slam events observed in the random wave model test programme derived from the recorded hull and wave surface motions. Prediction of slamming in this way requires firstly the identification of conditions for which a slam will occur and secondly the determination of the severity of the slam event in terms of the impulsive loading it applies to the hull. Clearly the relative motion of hull and encountered wave is an appropriate basis for this. Since it was not intended that an extremely lengthy full solution of the hydrodynamics of the bow would be solved within the global computation, the motion of the bow relative to the undisturbed wave surface was adopted for indication of slam occurrence and severity. Therefore conditions for the occurrence of a slam were based on the relative motion hull and wave surface whilst the severity of the slam was considered in terms of the relative velocity of bow and undisturbed wave surface when conditions for a slam were identified. Figure 13 shows range of the recorded maximum bow displacement relative to the undisturbed wave surface during the identified slam events for all test conditions. We see that the 
median maximum relative displacement is between 40 and $75 \%$ of the significant wave height, this

becoming smaller as the forward speed increases. Also this maximum relative motion is generally smaller for the highest and lowest wave modal periods tested. The upper and lower quartile ranges for the maximum relative motion are generally not large, being about $20 \%$ above and below the median value in most cases. Similar trends can be seen for both the significant wave heights tested. This relatively narrow range of relative motions indicates that it would be appropriate to use a relative bow displacement criterion for the identification of conditions for a slam to occur.
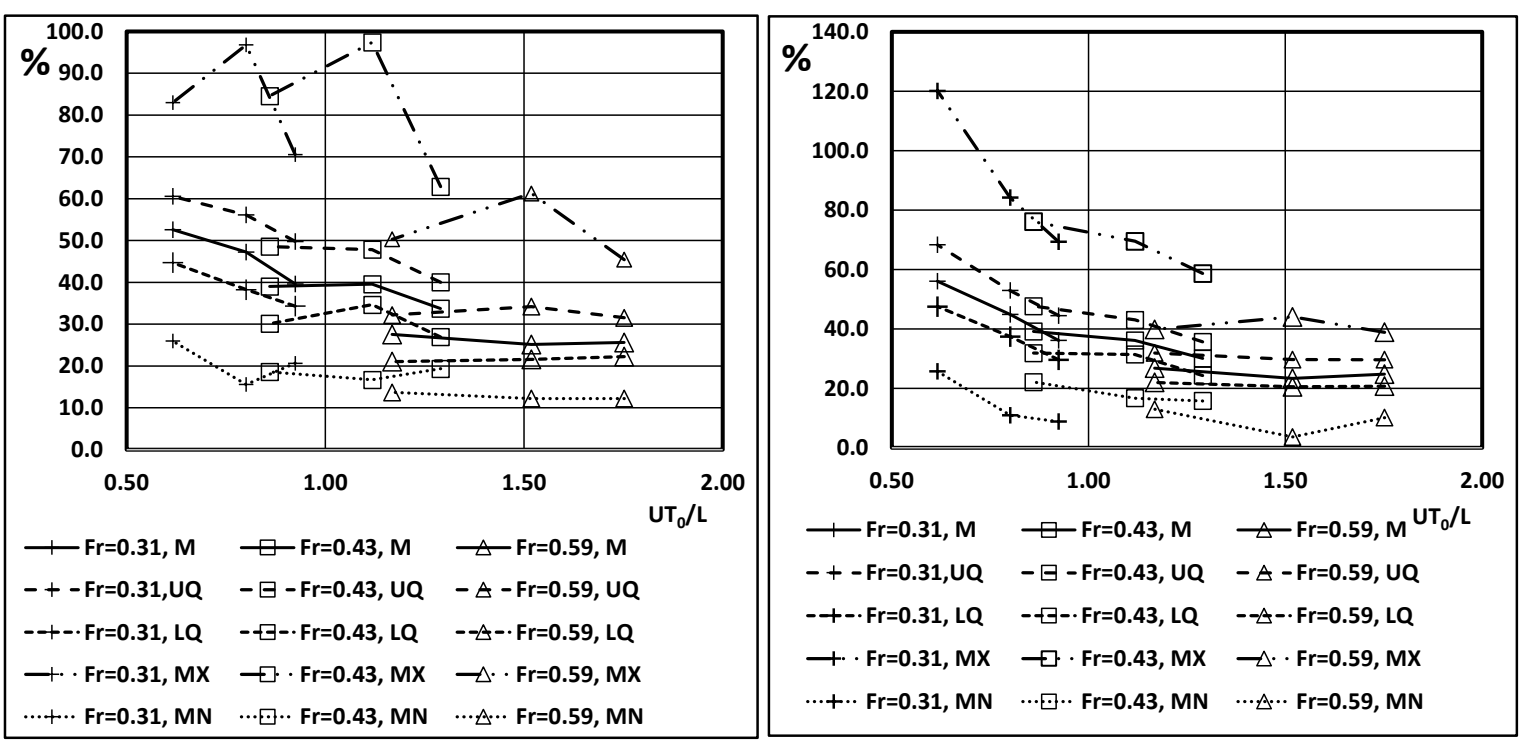

Figure 14: Peak relative vertical velocity during slam event as percentage of vessel forward speed and as a function of normalized modal wave period and Froude number (Median (M), upper quartile (UQ), lower (LQ) quartile, maximum (MX) and minimum (MN); wave height:

$$
\text { left- } 89 \mathrm{~mm} \text { and right }-78 \mathrm{~mm} \text { ). }
$$

For prediction of slam severity a number of kinematic indicators were considered including the relative velocity of hull and undisturbed wave profile. In regular waves a systematic relationship between the maximum relative velocity has been found between hull and undisturbed wave surface and the peak upward force in the consequent slam event (Lavroff et al., 2009; Lavroff and Davis, 2015). Figure 14 shows the median and quartile ranges for the maximum vertical relative velocity of hull and encountered wave surface in the present random wave tests, here normalized as a percentage of the forward speed of the vessel. We see that median values of the maximum relative 
vertical velocity prior to a slam event are between $25 \%$ and $55 \%$ of the forward speed and that these values reduce systematically as the normalized wave period increases. Upper and lower quartiles are again observed to be over a relatively small range, being approximately $25 \%$ above and below the median values. The maximum observed values are on average 1.9 times the median values. In all cases the relative velocity remains positive (i.e. the bow is moving towards the encountered wave profile) as would be expected.

\section{Computational simulation of slamming in random head seas}

The computational simulation was carried out using the two dimensional transient Green function solution (Holloway and Davis, 2002; Davis and Holloway, 2003) and implemented in a Fortran code program BEAMSEA. In this program the solution of water motion is carried out in a fixed frame of reference in the time domain for strips of the water mass set at right angles to the direction of motion. The solution for each strip develops in time as it is penetrated progressively by sections of the hull, commencing with the bow entering the strip and ceasing when the stern transom leaves the strip. The method thus accommodates forward speed effects as the solution for each strip has an initial condition on any given time step set by the solution inherited from the immediately adjacent section towards the bow for the previous time step. It is of course essentially a slender body approximation, but this is appropriate in the case of the high speed displacement hull forms of catamaran vessels with hull length to beam ratios of about 20:1. The solution proceeds incrementally in the time domain with one time step equal to the strip width divided by the forward speed. It has been found that using approximately 40 transverse water strips along the hull length gives satisfactory solutions at Froude numbers between 0.4 and 0.8 based on the overall hull length. The hull motion is integrated in time from the pressure distribution around all water strips in contact with the hull so that the hull motion and hydrodynamics are solved simultaneously in time. Within this computational framework a variety of other on the hull loadings can be included. In this case centre bow slam loads on the arch tops are applied when conditions for a slam are identified. The applied bow slam loads are set to a magnitude and duration according to 
loads during the time domain computation consideration is given not only to the median values of slam parameters identified in the model test program, but also to the random variations which were observed.

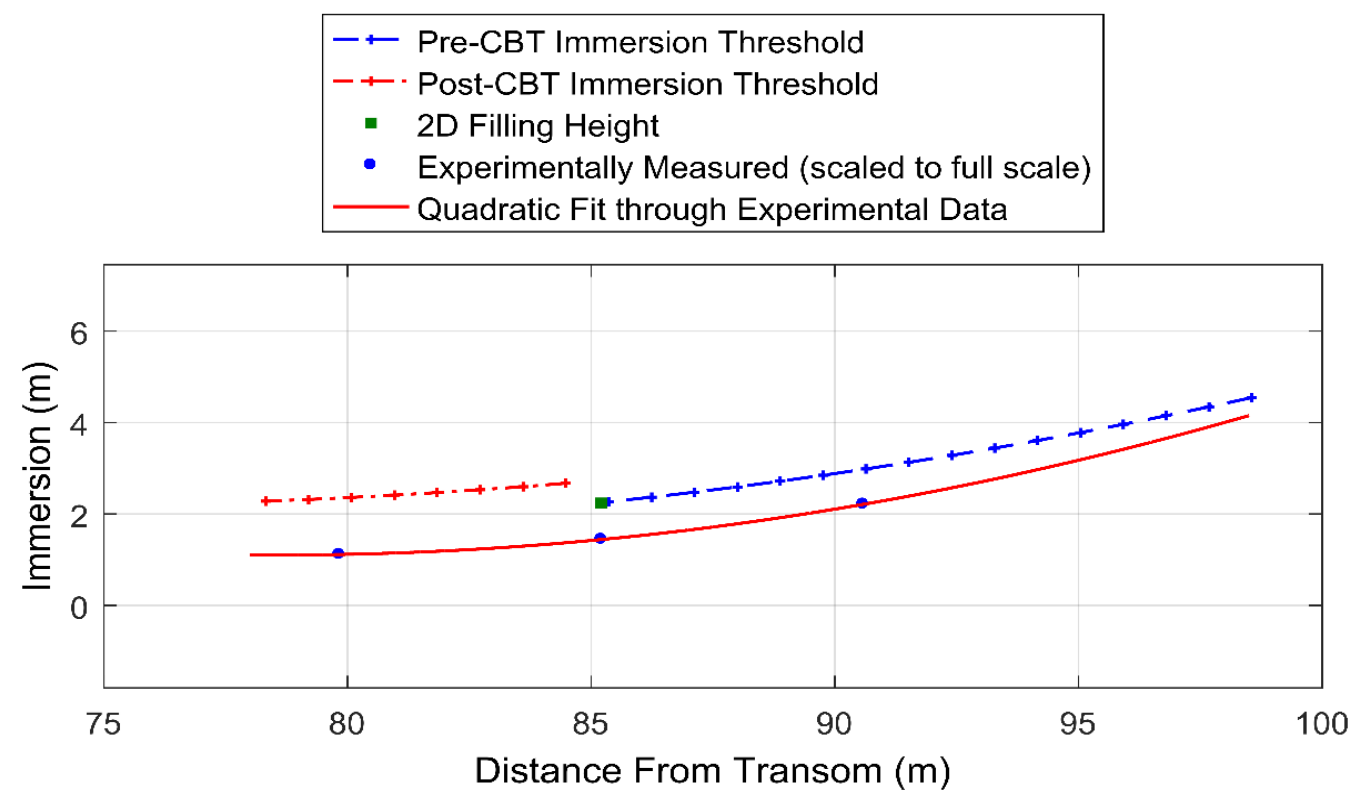

Figure 15: Bow relative vertical displacement (i.e. the relative immersion, $\mathrm{m}$ ) filling threshold based on sectional geometry (ahead of and aft of the centre bow truncation (CBT) and filling height at the CBT) and the experimentally observed relative displacement for a slam to occur as functions of location along the vessel.

The method for identifying a slam condition is based on a two-dimensional filling height concept, where the cross-sectional two dimensional filling height is calculated at locations forward and aft of the centre bow truncation. The two dimensional filling height is the height to which the undisturbed wave surface must rise at any section relative to the hull in order that water contained between the hulls would rise to the top of the arches between the centre bow and demi-hulls on a two dimensional basis. This was determined by taking two dimensional cross sections and calculating tunnel areas from a computer-drafted three dimensional model. Figure 15 shows a broadly quadratic trend for two dimensional filling heights ahead of and aft of the centre bow 
truncation. The discontinuity in the trend arises from the sudden termination of the centre bow, resulting in an increased two-dimensional filling height at locations aft of the centre bow truncation. The height in the tunnel continues to decrease behind the centre bow truncation and so reduces the filling height slowly in the aft direction. The slam identification curve from the model tests observed with a model hull mounted wave probe is also included in Figure 15. There are similar trends in the region where most of the slam action occurs, close to the centre bow truncation. The discontinuity in the geometric method results in very few slams being predicted aft of the CBT. However, fewer slams were observed in that region and we see from the model tests that the relative vertical displacement of the bow to the undisturbed wave surface when a slam occurred was found to be generally less than the two dimensional filling height at the identified location of a slam. This is most probably caused by the effect of forward speed and flow around the whole bow as it enters the water prior to the slam. The experimentally determined curve shown represents the mean threshold relative vertical displacement as a function of position along the vessel, $I_{\mathrm{e}}=c_{0}+c_{1} x+c_{2} x^{2}$, where $c_{0}, c_{1}, c_{2}$ are coefficients determined from a regression analysis of the test data and $x$ is distance from the transom. Conditions for a slam to occur thus involve the vertical position of a particular section of the centre bow $\left(I_{C B}\right)$ relative to the undisturbed wave surface and the change in this relative position relative to the previous time step $d I_{C B} / d t$. A slam event is deemed possible when both the relative displacement at a bow section and the rate of change in relative displacement over one time step are positive (i.e. the bow section must be sufficiently displaced relative to the undisturbed water surface and that relative displacement must be reducing). A linear regression analysis of the test data was also undertaken to include the effect of forward speed of the vessel $(U)$ on the average relative displacement required for a slam event to occur, $I_{\mu C B}=a_{0}+a_{1} U$.

Conditions for a slam event also involve variability of the threshold relative vertical bow displacement. From the model test data the residuals of the observed slam relative bow displacements were determined and found to approximate a normal distribution as shown in Figure 
16. We thus introduce in the computation a random variation about the average relative bow displacement for slams to occur. The variance of this normal distribution is then used to modify the threshold relative bow displacement criterion applied in the computation, making $I_{s}=I_{\mu}+\varepsilon$ where $I_{s}$ is the slam relative bow displacement threshold used during the motion computation, $I_{\mu}$ is the predicted mean relative bow displacement for slamming to occur and $\varepsilon$ is an independent and identically distributed random displacement based on the observed residual distribution shown in Figure 15. When the relative bow displacement of a bow section equals or exceeds the relative bow displacement threshold $I_{s}$ at any section a slam event is initiated in the computation. Relative bow displacements were calculated at 24 locations along the vessel and as soon as the relative bow displacement criteria is fulfilled at any one of these locations, a slam event is triggered and no more slams are possible until the current event is completely resolved. The slam load is then applied at the location where the slam was first triggered.
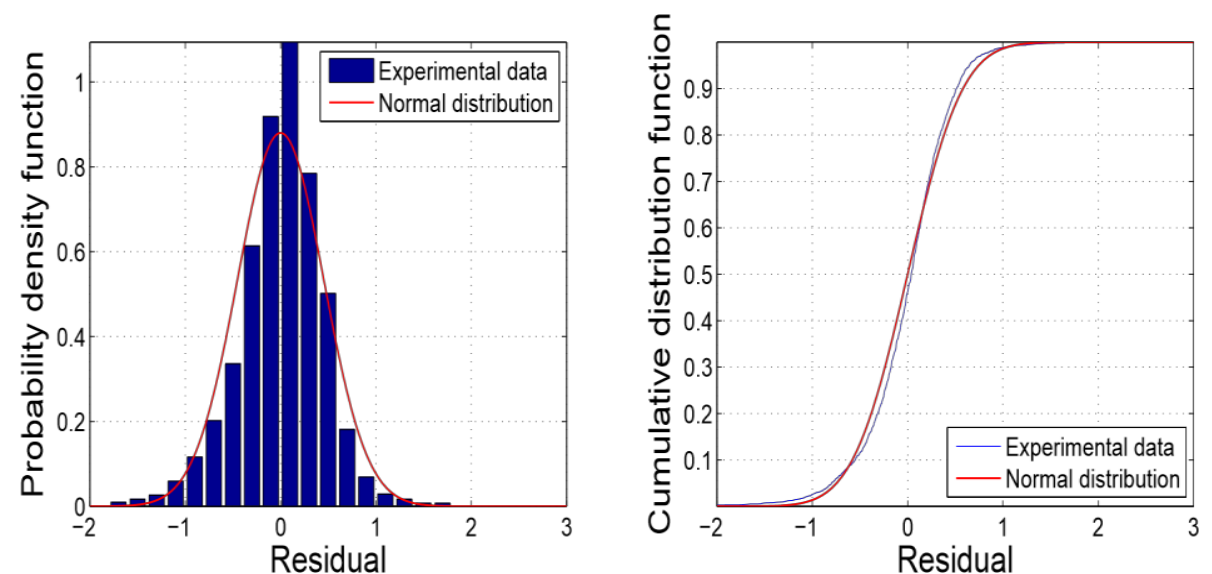

Figure 16: Probability density function and cumulative distribution function of the normalized residual of bow relative bow displacement for observed slams

The slam force prediction was initially considered on the basis of 25 different variables observed in the model tests, such as forward and aft demihull VBM, water surface elevations and the bow vertical motion relative to the encountered wave. A preliminary correlation analysis was conducted on all 25 variables by calculating Pearson's correlation coefficient, and Spearman's rank correlation coefficient for each variable against each other variable. Preliminary analysis then 
eliminated some variables, leaving ten potentially important indicators of slam characteristics. These variables were the slam load on the centre bow, centre bow relative bow displacement, relative vertical velocity at slam instant, maximum relative vertical velocity prior to slam event, pitch angle, maximum pitch angle prior to slam, pitch velocity at slam instant, maximum pitch velocity prior to slam event, slam location and vessel forward speed.

\begin{tabular}{|r|c|c|c|c|c|c|c|c|c|l|}
\hline & $F_{S}$ & $I$ & $V_{\max }$ & $V_{\text {rel }}$ & $L o c$ & $x_{50}$ & $x_{50 \max }$ & $x_{50}^{\prime}$ & $x_{50 \max }^{\prime}$ & $U$ \\
\hline$F_{s}$ & 1.00 & 0.36 & 0.45 & 0.58 & 0.28 & -0.48 & -0.46 & 0.17 & -0.54 & 0.00 \\
\hline
\end{tabular}

Table 3: Pearson product-moment correlation coefficients, $r$, for the slam force $\left(F_{s}\right)$ with other variables (bow relative bow displacement $(I)$, maximum relative velocity $\left(V_{\max }\right)$, relative velocity at slam instant $\left(V_{r e l}\right)$, slam location $(L o c), \operatorname{pitch}\left(x_{50}\right)$, maximum pitch $\left(x_{50 \mathrm{max}}\right)$, pitch rate $\left(x_{50}^{\prime}\right)$, maximum pitch rate $\left(x^{\prime}{ }_{50 \max }\right)$, forward speed $\left.(U)\right)$.

The correlation coefficient of the selected variables is shown in Table 3. Slam load $\left(F_{s}\right)$ shows the highest correlation to relative vertical velocity when the slam occurred $\left(V_{r e l}\right)$ and it also has moderate correlations with pitch angle (both maximum and instantaneous) and maximum pitch velocity prior to slam $\left({ }^{\prime} x_{50 \max }\right)$. Vessel speed, $U$, has only a small correlation with slam load. This is attributed to testing only three different speeds, however it was found that the inclusion of this variable reduced the residual variance. Spearman's rank correlation coefficients showed broadly the same outcomes for the chosen variables. One exception was the centre bow relative displacement for which the Pearson correlation coefficient was rather small (0.36) while the Spearman coefficient is considerably greater (0.68), suggesting that the relation is not modelled well on a linear basis. Whilst the slam force thus correlates best with the relative velocity at the slam instant, it also correlates quite strongly with pitch and pitch rate, but these of course are strong contributors to the relative bow motion which combines pitch, heave and water surface motions. It was concluded that the vertical velocity of the bow relative to the encountered water surface profile at the instant a slam was identified as occurring was the most appropriate indicator of the 
consequent slam force, but this relation was of course subject appreciable variability in random sea conditions. The slam load and its moment are applied to the LCG of the vessel within the overall hull motion computation in the time domain.

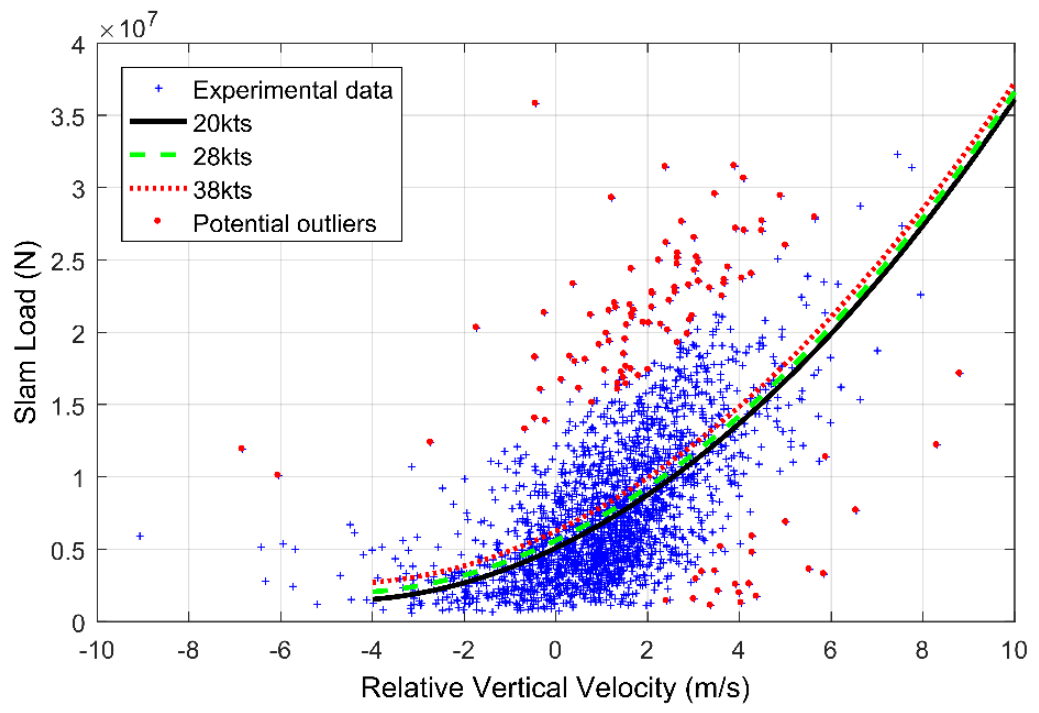

Figure 17: Slam loads predicted from motion data in model tests, showing the median slam load prediction equation for three different full scale vessel speeds.

The slam load calculation procedure thus consisted of two components, a deterministic part and a stochastic element based on the residual of the deterministic fit. The predicted load equation was based primarily on relative vertical velocity at the centre bow truncation, $L p=a_{0}+a_{1} V_{r e l}+a_{2} V_{r e l}^{2}$ $+a_{3} U$, where $a_{0}, a_{1}, a_{2}$ and $a_{3}$ are regression coefficients based on fitting the test data, $V_{r e l}$ is the relative vertical velocity at the slam event time and location and $U$ the forward speed of the vessel. Figure 17 shows the predicted slam load for three different speeds as a function of relative vertical velocity, potential outlying data points being identified. These outliers were detected by normalizing the residuals. If a residual was found to be larger than expected in $95 \%$ of observations then it was considered an outlier. However, in view of the extreme nonlinearity of the bow slam process outlier data points were retained in the regression so as to model the more extreme events. The residual from the multi-dimensional fit to the model test data is then used to form the stochastic element of the slam model. A lognormal distribution gave a poor fit and the resulting 
slam loads $L_{\text {slam }}$ were found to be generally smaller than the experimental results. This is due to a stochastic slam factor, $F_{\text {slam }}$ being less than expected where $L_{\text {slam }}=F_{\text {slam }} L_{p}$. Therefore, rather than using standard Weibull or Rayleigh distributions, it was decided to base the variability on an empirical cumulative distribution. The empirical cumulative distribution function is shown in Figure 18 and Table 4 gives the numerical values. Thus within the time domain seakeeping code, when a slam is identified as occuring, a uniformly distributed random number is generated and the resulting stochastic slam factor $F_{\text {slam }}$ is interpolated from the tabulated cumulative distribution function.

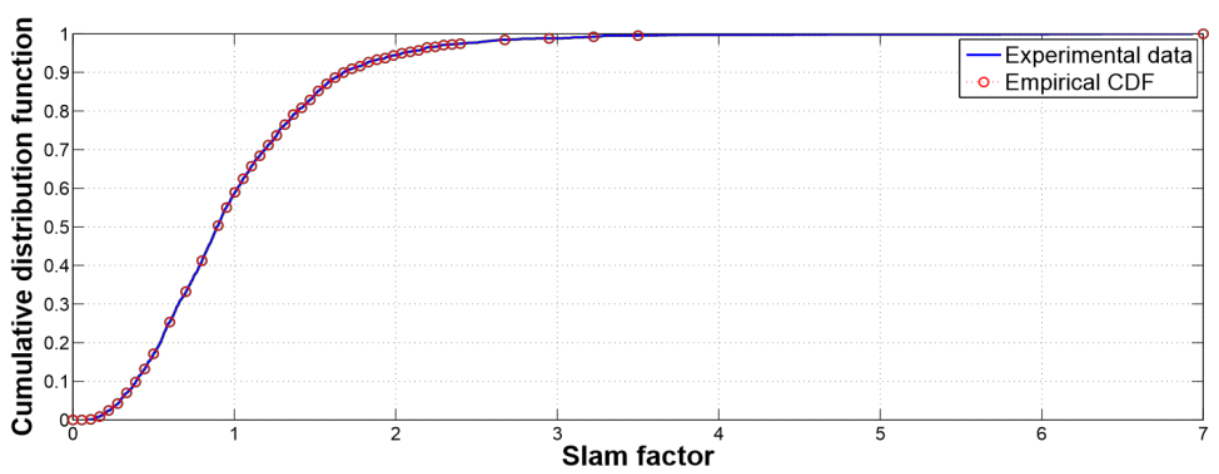

Figure 18: Empirical cumulative distribution function of the scaled residual of the predicted slam load factor $F_{\text {slam }}$.

In modelling the slam loading within the computation, the rise time and duration of the slam also need to be considered. Here again reference is made to the experimental data for average values and variability: a prediction of an average value was made and was then modified by an experimentally based stochastic factor. Mild correlation was found between slam duration and relative bow displacement at the centre bow truncation $(r=0.39)$, and duration and forward speed $(r=-0.513)$. An ordinary least squares regression was used to calculate a predicted average slam duration, which at full scale was then given by $t_{a}=b_{0}+b_{1} U+b_{2} I$, where $b_{0}=0.3944 \mathrm{~s}, b_{1}=-0.0085$ $\mathrm{s}^{2} / \mathrm{m}, b_{2}=0.0279, U$ is the forward speed of the vessel and $I$ is the relative bow displacement at the centre bow truncation at the time that the slam is identified. It was found from the experimental data that the residuals of this least squares fit approximated a lognormal distribution, as shown in Figure 19. 


\begin{tabular}{|c|c|c|c|c|c|c|c|}
\hline$\varepsilon$ & $F_{\text {slam }}$ & $\varepsilon$ & $F_{\text {slam }}$ & $\varepsilon$ & $F_{\text {slam }}$ & $\varepsilon$ & $F_{\text {slam }}$ \\
\hline 0.0013 & 0.1111 & 0.5499 & 0.9517 & 0.8864 & 1.6241 & 0.9662 & 2.2448 \\
\hline 0.0088 & 0.1667 & 0.5894 & 1.0034 & 0.8995 & 1.6759 & 0.9708 & 2.2966 \\
\hline 0.0245 & 0.2222 & 0.6246 & 1.0552 & 0.9094 & 1.7276 & 0.9724 & 2.3483 \\
\hline 0.0424 & 0.2778 & 0.6572 & 1.1069 & 0.9162 & 1.7793 & 0.9743 & 2.4000 \\
\hline 0.0701 & 0.3333 & 0.6842 & 1.1586 & 0.9266 & 1.8310 & 0.9842 & 2.6750 \\
\hline 0.0980 & 0.3889 & 0.7117 & 1.2103 & 0.9328 & 1.8828 & 0.9879 & 2.9500 \\
\hline 0.1319 & 0.4444 & 0.7368 & 1.2621 & 0.9372 & 1.9345 & 0.9921 & 3.2250 \\
\hline 0.1713 & 0.5000 & 0.7649 & 1.3138 & 0.9438 & 1.9862 & 0.9952 & 3.5000 \\
\hline 0.2533 & 0.6000 & 0.7907 & 1.3655 & 0.9495 & 2.0379 & 1.0000 & 7.0000 \\
\hline 0.3320 & 0.7000 & 0.8083 & 1.4172 & 0.9534 & 2.0897 & & \\
\hline 0.4213 & 0.8000 & 0.8727 & 1.4690 & 0.9569 & 2.1414 & & \\
\hline 0.5034 & 0.9000 & 0.8704 & 1.5724 & 0.9644 & 2.1931 & & \\
\hline
\end{tabular}

Table 4: Slam factor table. $F_{\text {slam }}$ is the slam load multiplying factor which is interpolated from a uniformly distributed random number between points shown in column $\varepsilon$.

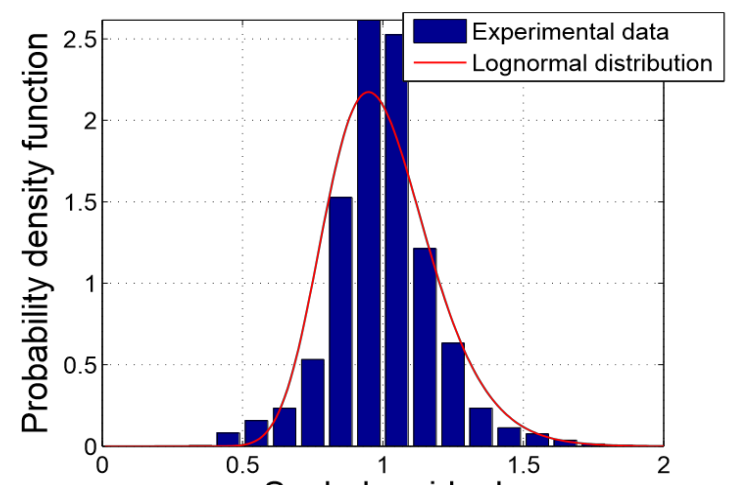

Scaled residual

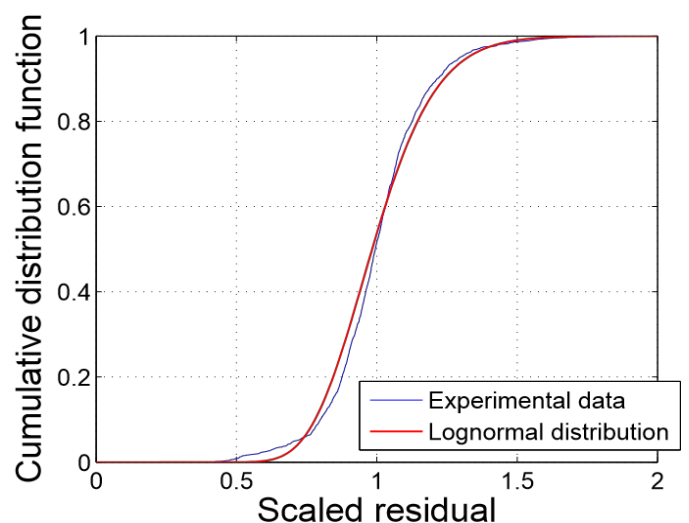

Figure 19: Probability density function and cumulative distribution function of the scaled residual of the predicted slam duration compared with the respective lognormal distribution.

When a slam is identified in the simulation, the slam duration was calculated as $t_{d}=t_{a} \varepsilon_{t}$, where $\varepsilon_{t}$ is an independent and identically distributed random number based on the observed distribution of the scaled residuals. When the vessel is sailing at $38 \mathrm{kts}(19.55 \mathrm{~m} / \mathrm{s})$, the predicted slam duration is approximately $0.3 \mathrm{~s}$ and from the standard deviation the factor $\varepsilon_{t}$ generally falls between 0.6 and 1.4. Therefore the slam duration is expected to be in the range of 0.18 to $0.42 \mathrm{~s}$. The time step applied in the time domain seakeeping code is approximately $0.06 \mathrm{~s}$ at $38 \mathrm{kts}$ and therefore a typical 
slam event occurs over 3 to 7 computational time steps. During this time, the slam load is ramped from zero up to a maximum and then back to zero.

The rise time component of the overall slam calculation (expressed as a fraction of slam duration) was based on the observed rise time distribution. The rise time distribution (Figure 20) appeared to be bimodal with distinct local maxima at 0.25 and 0.5 . These modal maxima can be attributed to the double peaks observed in the test data as shown in Figure 9 and to the transient vibratory response of the model hull.

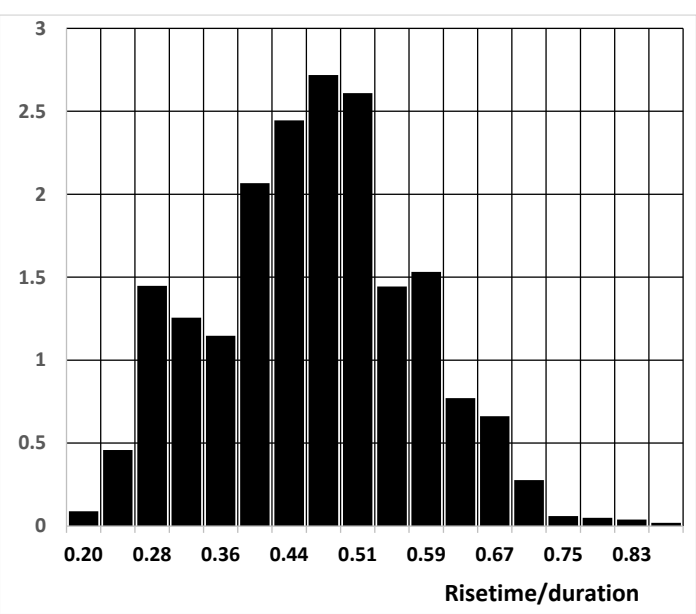

Figure 20: Probability density function of the slam rise time as a fraction of the slam duration

The probability density function of the observed distribution can be represented by the equation $M=p \varphi_{1}+(1-p) \varphi_{2}$, where $\varphi_{1}$ and $\varphi_{2}$ are normal distributions representing the two modes of the distribution and the mixing proportion $p$ represents the relative dominance of each distribution. The approximate bimodal distribution was determined by applying an iterative expectation maximization algorithm. In this case, the mixing proportion $p$ was found to be 0.14 , that is $14 \%$ of slam rise times are drawn from the first distribution with the remainder determined from the other.

With the slam duration and rise time known, a piecewise linear function is introduced in the motion computation to ramp the maximum slam load $F_{s}$ from zero at the start of the slam event to a maximum at the rise time and back to zero at the end of the slam duration. Since only a constant slam load can be applied over each time step, the piecewise linear function is averaged over each time step. Figure 21 shows a typical slam load time variation scaled to full scale, where an observed 
slam is compared to the numerically modelled slam, both being normalized to the maximum load. In this case the load reached a peak at about $0.07 \mathrm{~s}$ and a small secondary peak is evident in the model test data at $0.21 \mathrm{~s}$. The secondary peak is neglected when determining the slam load input to the motion computation which comprised a linear ramp up and down about the peak. The total duration of the slam is divided into a number of time steps, in this particular instance the seakeeping code time step is $0.06 \mathrm{~s}$ and the measured slam duration is $0.29 \mathrm{~s}$. The slam duration is rounded to the next whole time step $(0.3 \mathrm{~s})$. Here the total slam duration is five time steps.

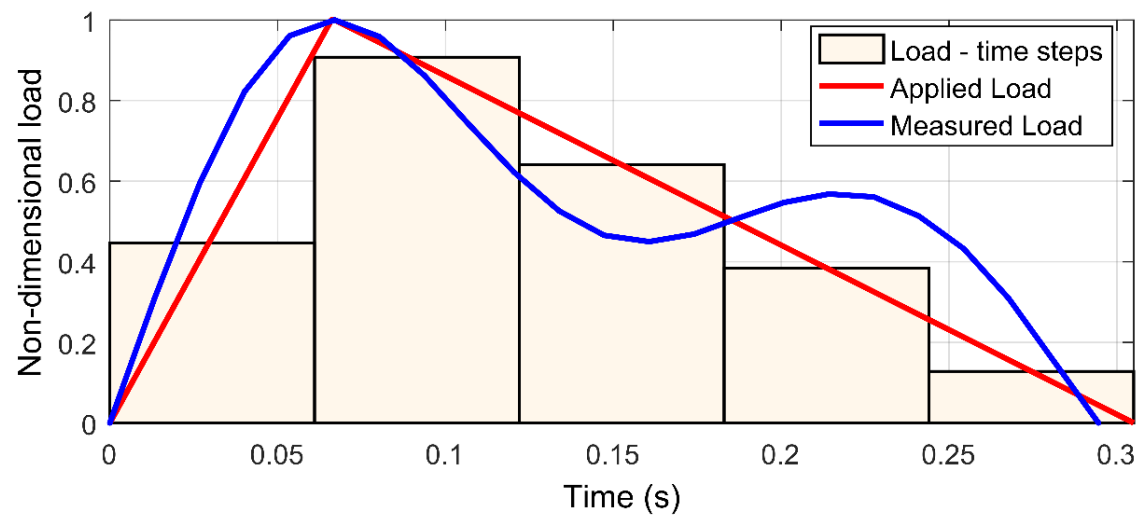

Figure 21: Typical slam load-time profile, showing measured experimental data and the bilinear approximation applied in the motion computation.

With the slam duration and rise time known, a piecewise linear function is introduced in the motion computation to ramp the maximum slam load $F_{s}$ from zero at the start of the slam event to a maximum at the rise time and back to zero at the end of the slam duration. Since only a constant slam load can be applied over each time step, the piecewise linear function is averaged over each time step. Figure 21 shows a typical slam load time variation scaled to full scale, where an observed slam is compared to the numerically modelled slam, both being normalized to the maximum load. In this case the load reached a peak at about $0.07 \mathrm{~s}$ and a small secondary peak is evident in the model test data at $0.21 \mathrm{~s}$. The secondary peak is neglected when determining the slam load input to the motion computation which comprised a linear ramp up and down about the peak. The total 

seakeeping code time step is $0.06 \mathrm{~s}$ and the measured slam duration is $0.29 \mathrm{~s}$. The slam duration is rounded to the next whole time step $(0.3 \mathrm{~s})$. Here the total slam duration is five time steps.

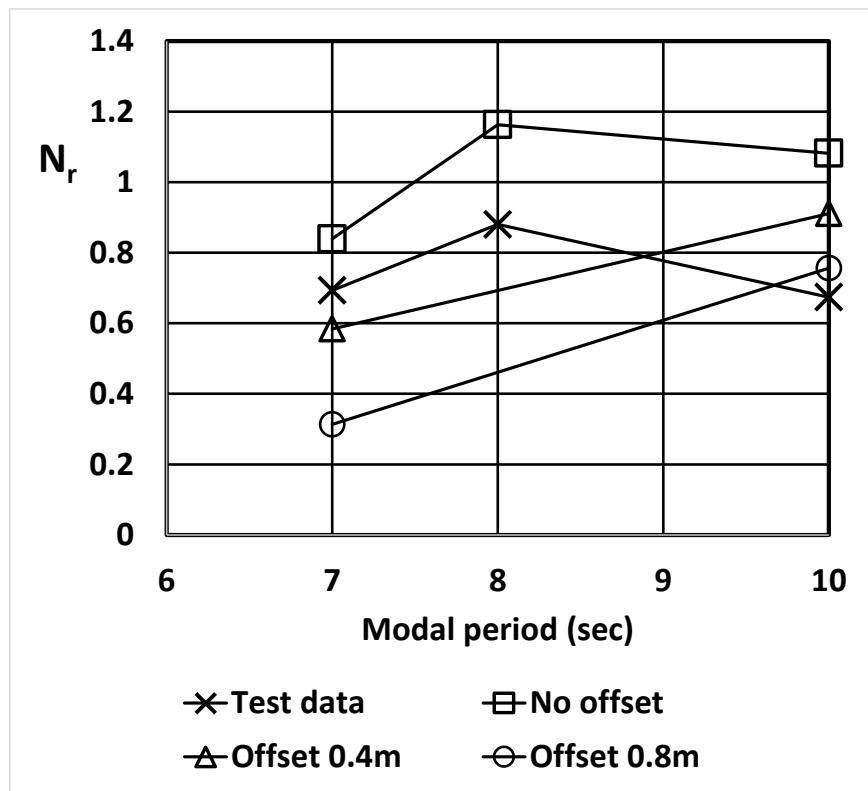

Figure 22: Normalized slam occurrence rates $\left(\mathbf{N}_{\mathbf{r}}=(\right.$ slam rate $) \times($ hull length $) /$ (hull speed)) from model tests data and computed rates with different vertical offsets of slam trigger threshold. Significant wave height $4.0 \mathrm{~m}$, speed 38 knots. Significant wave height $4.0 \mathrm{~m}$, speed 38 knots. To verify the slam computation method slam occurrence rates, loads and locations are considered. Figure 22 compares the slam occurrence rates observed in the model tests with rates computed with three additive corrections (zero, $0.4 \mathrm{~m}$ and $0.8 \mathrm{~m}$ ) to the slam occurrence threshold. The predicted slam rates are based on the relative bow displacement to the undisturbed wave surface which produces randomized filling of any bow section on a two dimensional basis at any of 24 sections along the bow. The positive additive corrections are such that slams are predicted with a larger relative displacement. Three conditions are shown for a significant wave height of $4.0 \mathrm{~m}, \mathrm{a}$ speed of $38 \mathrm{kts}$ and with modal periods $7,8.5$ and 10 seconds. The occurrence rates were calculated over a 20 minute simulated time period. We see that with no correction to the occurrence threshold the identification method over predicts slam occurrences, whereas application of an additive correction to the threshold progressively reduces the predicted slam occurrence rate as would be 
expected. The filling height correction required to match scale model results varies with modal period: for the $7 \mathrm{~s}$ modal period condition, a filling height correction of approximately $+0.2 \mathrm{~m}$ would best match the test data and for the $10 \mathrm{~s}$ modal period a correction of approximately $0.95 \mathrm{~m}$ is required. This variation is attributed to three dimensional flow effects in the bow area which will modify the manner in which cross section fills and a slam occurs. Figure 23 shows the motion of the bow relative to the undisturbed wave surface profile with markers to show identified slams. Slams are identified where the approach velocity of the bow to the wave surface is close to a maximum and when the relative motion exceeds that required to fill the arch section on a two dimensional basis. However the slams occur when the relative motion remains less than that for the undisturbed surface level to reach the top of the arched section and thus the rise of water displaced by bow entry is the cause of the slam.
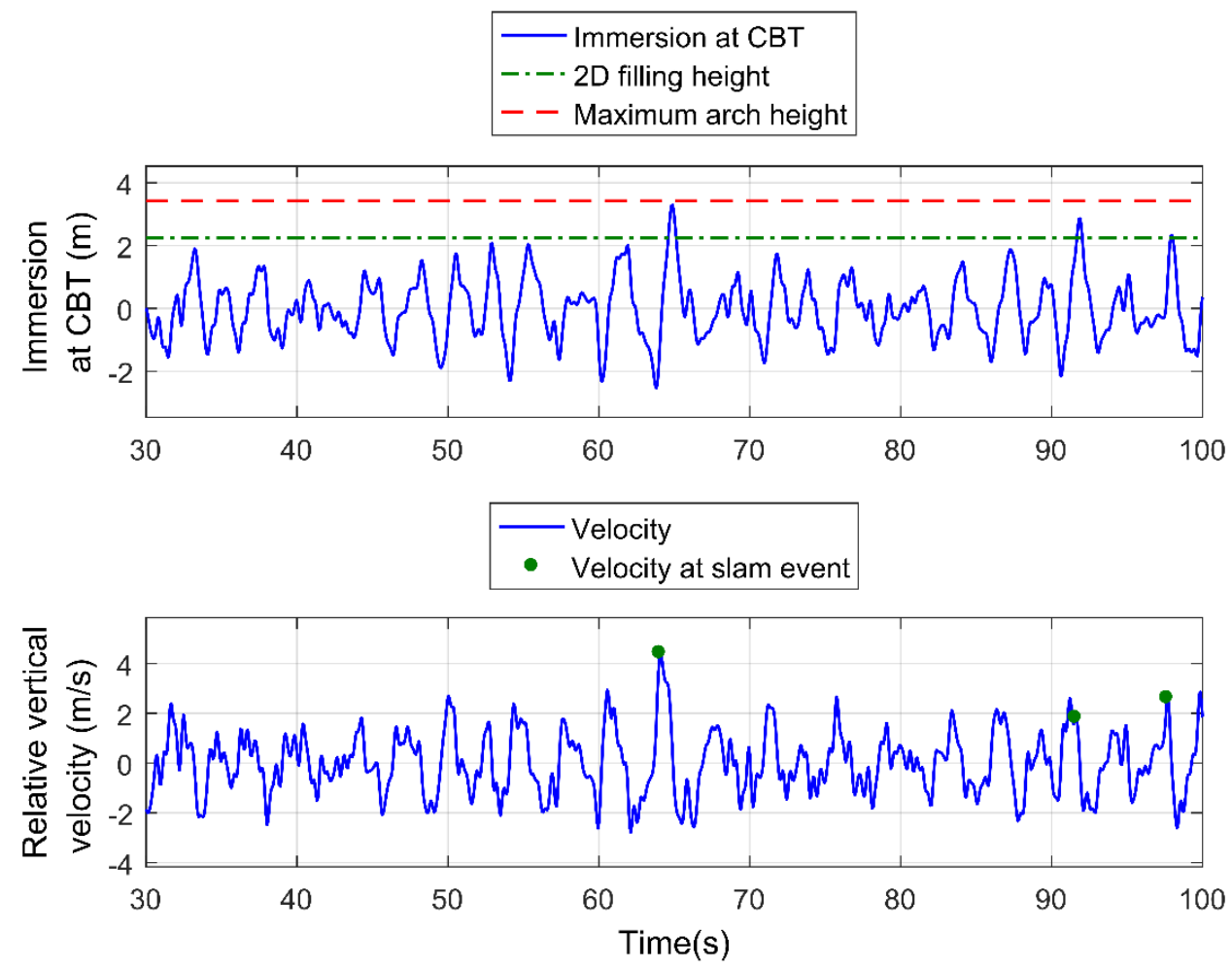

Figure 23: Time-domain simulation of a $112 \mathrm{~m}$ wave-piercing catamaran at $38 \mathrm{kts}$ in head seas

(wave height $3 \mathrm{~m}$, modal period 7s JONSWAP wave spectrum) showing relative bow displacement at the CBT (labelled immersion) and relative vertical velocity (+ve represents the hull and wave moving towards one another, slam events shown by markers). 


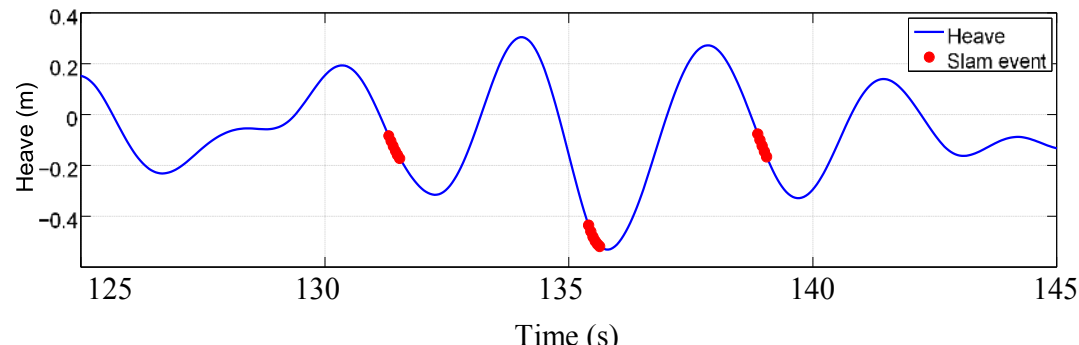

(a) Heave

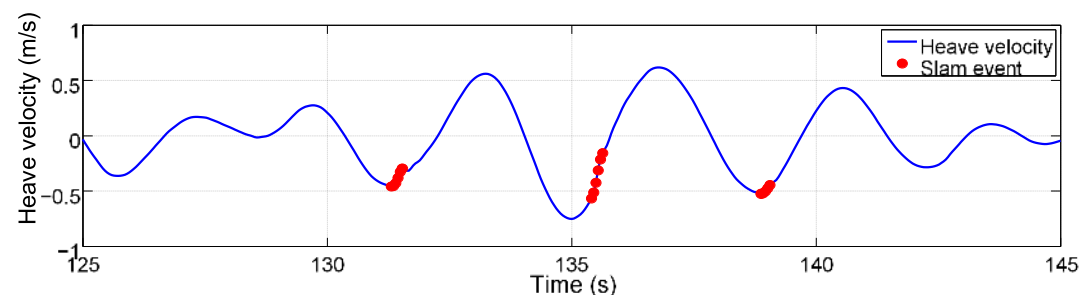

(b) Heave velocity

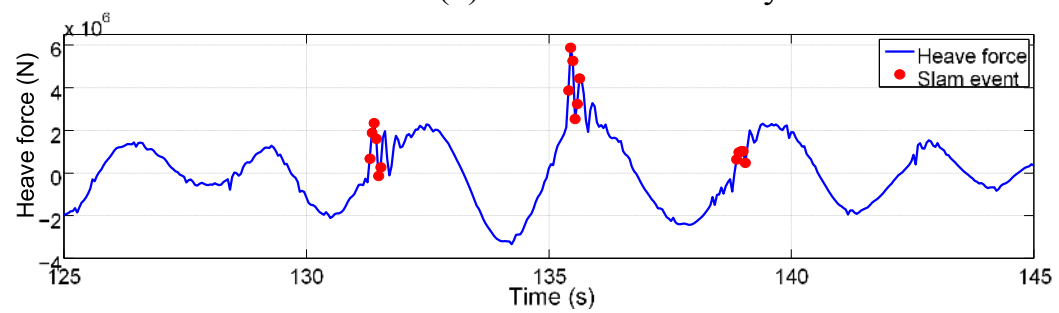

(c) Bow upward force

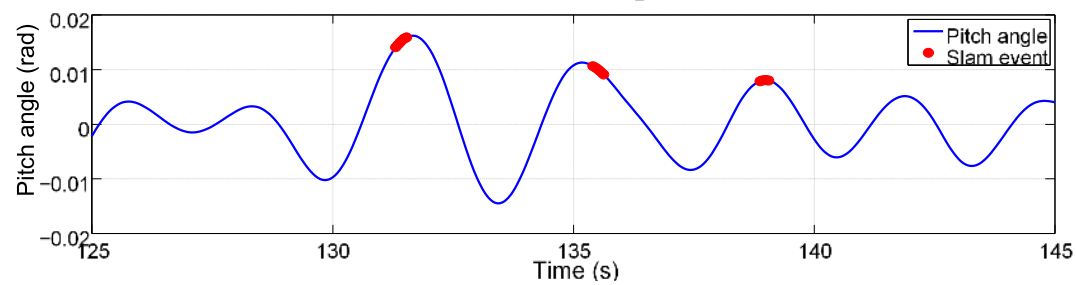

(d) Pitch angle



(e) Pitch velocity

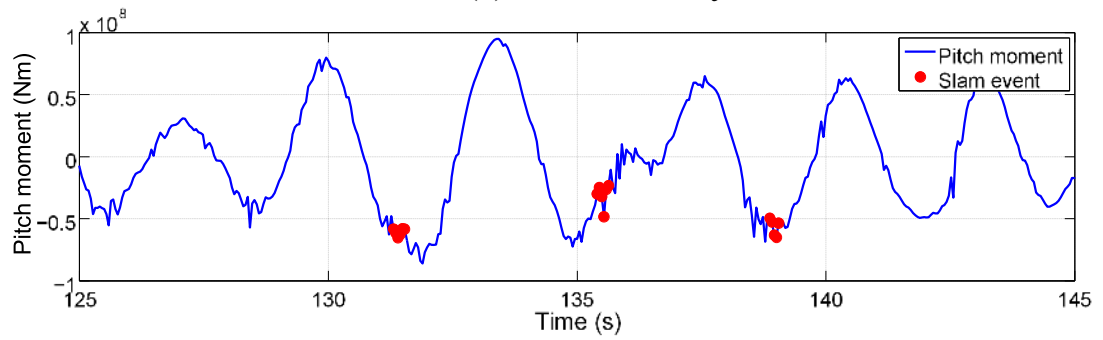

(f) Pitching moment

Figure 24: Computed motions and loads showing three slam events (each identified by a group of computed points) at 131s, 135.4s and 138.9s. Significant wave height $H_{1 / 3}=$ 
A selection of heave and pitch time traces from the simulation are shown in Figure 24. Each marked point represents a time step where a slam is occurring. During the 20 s of data shown, three slams have occurred on three consecutive waves. The first two slams are six time steps in duration $(0.22 \mathrm{~s}$ duration $)$ and the third one has a duration of five time steps $(0.18 \mathrm{~s})$. The second slam event is the largest, applying a slam load of $5.8 \mathrm{MN}$ at its peak. The maximum load of the first slam is $2.4 \mathrm{MN}$ and the third slam is relatively minor at $1.0 \mathrm{MN}$. The slam events are too short in duration to substantially change the global motion of the ship, as shown in the heave and pitch time traces. However the effect of the second slam on the heave velocity and pitch velocity is noticeable. Although none of these slams change the direction of motion of the vessel, significant deceleration is observed, particularly in heave.

(a) Experimentally measured (scaled)

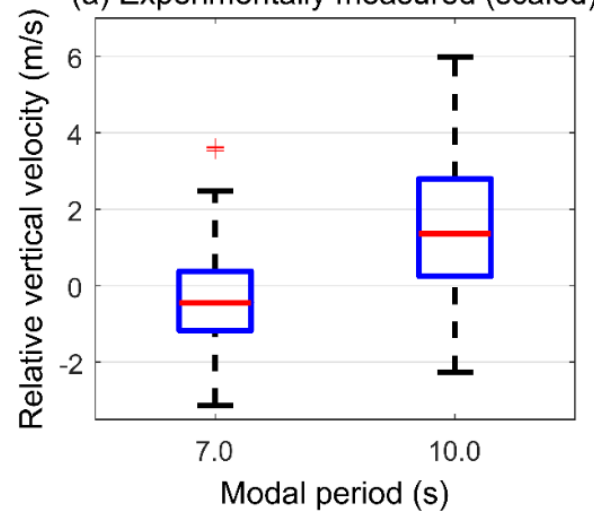

(b) From simulation

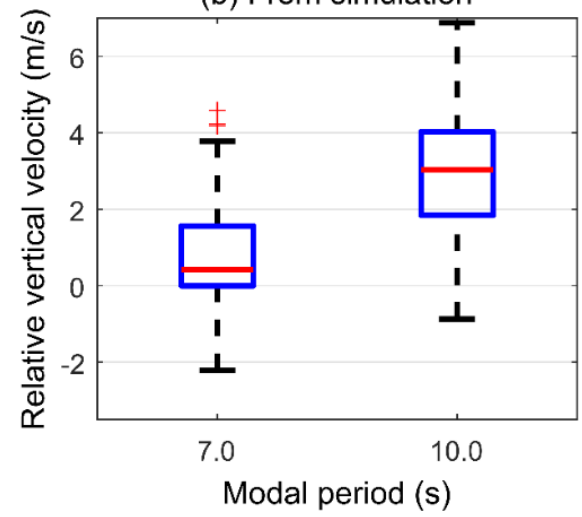

Figure 25: Comparison between (a) experimentally measured and (b) simulated relative vertical velocity distributions at the CBT when slams are identified (significant wave height $4 \mathrm{~m}$, vessel speed 38kts). Box shows quartile range, markers show extreme values.

Figure 25 shows a comparison between distributions of experimentally measured and simulated relative vertical velocity at the slam instant for $7 \mathrm{~s}$ and $10 \mathrm{~s}$ modal periods. The experimental data shows that slams tend to occur in the $7 \mathrm{~s}$ period condition when the relative vertical velocity is small and often negative, that is when the CBT and undisturbed wave are moving apart. This comes about because the relative velocity is being determined relative to the undisturbed encountered wave surface, whereas the actual water surface which causes the slam is substantially disturbed 
by the entry of bow and demi-hulls prior to the arch filling and the slam occurring. Nevertheless we see that there is general agreement between the experimental observations and the results of the numerical simulation. For the 10 s period there is a greater variance and the majority of slam events occur when the wave and ship are moving together at the CBT. Whilst the computed results show broadly similar outcomes, slams generally occur in the simulation at a rather greater relative vertical velocity.

(a) Experimentally measured (scaled)

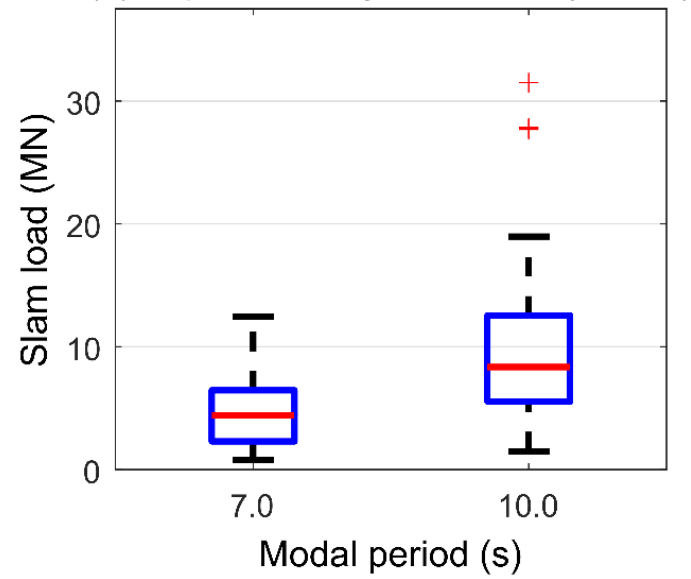

(b) From simulation

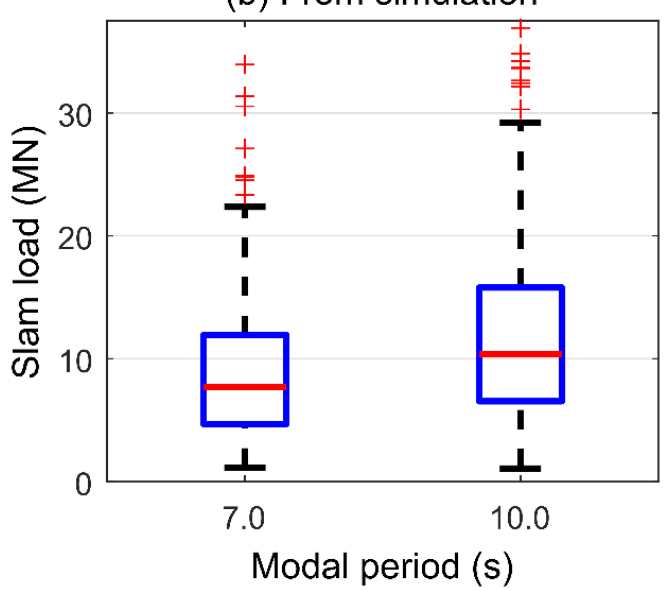

Figure 26: Comparison between (a) experimentally measured (scaled to full scale) and (b) simulated slam loads (significant wave height $4 \mathrm{~m}$, vessel speed $38 \mathrm{kts}$ ).

The corresponding slam load distributions are shown in Figure 26. As expected the experimental data shows relatively smaller slam loads for the $7 \mathrm{~s}$ modal period condition than for the 10 s condition, with two extreme events detected in the latter condition. Slam load distributions from the simulation are more spread than the experimentally measured results and more outliers are present although the most extreme slams identified are of similar magnitude in the experimental tests and simulation. The median slam load from the simulation slightly exceeds the experimentally measured median. The $7 \mathrm{~s}$ modal period condition has a smaller variance and median than the 10 s condition, which can be attributed to the smaller variance and median of relative vertical velocity distribution. These results verify that the slam computation is behaving broadly as observed in the experiments but that the seakeeping simulation has a tendency to 
somewhat over predict relative vertical velocities and thus slam loads. It thus appears that the simulation is generally conservative.

\section{Application to service slamming predictions}

To illustrate the application of the slamming prediction method, seas conditions prevailing on the Tsuguru Strait service between Aomori, Honshu and Hakodate, Hokkaido, will be considered. Two $112 \mathrm{~m}$ class INCAT vessels of the type modelled in the tank test program operate this route. Sea conditions prevailing on this route are broadly representative of routes often operated by this class of vessel, the route length being $113 \mathrm{~km}$ with an average transit time of 1 hour, 45 minutes at 35kts (Roberts, 2005). It should be borne in mind that at this stage the model test program has only provided slamming data results for head seas and so the results to be presented must be seen as illustrative only as not all crossings would experience head seas. Therefore, we will here consider only slamming occurrence when sailing into head seas of wave height and modal period corresponding to conditions on this particular route. Wave height and modal period data (Roberts, 2005) is shown in Table 5 as a percentage of crossings at each wave height and modal wave period.

\begin{tabular}{|c|c|c|c|c|c|c|c|r|}
\hline & \multicolumn{9}{|c|}{ Modal period (s) } \\
\hline Significant wave height $(\mathrm{m})$ & 3 & 4 & 5 & 6 & 7 & 8 & 9 & \multicolumn{1}{l|}{10} \\
\hline 0.5 & 2.9 & 10.5 & 6.2 & 1.7 & 0.5 & & & \\
\hline 1 & 1.4 & 11 & 11.9 & 5.3 & 1.2 & 0.1 & & \\
\hline 1.5 & & 2.4 & 8 & 8.2 & 3.2 & 0.5 & 0.1 & 0.2 \\
\hline 2 & & & 3.9 & 5.2 & 2.8 & 0.8 & & \\
\hline 2.5 & & & 0.3 & 2.3 & 2.9 & 0.9 & & \\
\hline 3 & & & & & 1.3 & 0.8 & 0.2 & \\
\hline 3.5 & & & & & 0.3 & 0.7 & 0.2 & \\
\hline 4 & & & & & & 0.9 & 0.3 & 0.1 \\
\hline$>4$ & & & & & & 0.3 & 0.4 & 0.1 \\
\hline
\end{tabular}

Table 5: Wave height and modal period data for the Tsugaru Strait (percentage of crossing

$$
\text { voyages, (Roberts, 2005)) }
$$

Simulations were run for each condition. When a slam event was not detected in 15 minutes of simulated sea time, it was concluded that that particular condition was too mild for slamming and no more computation was conducted. After conducting all simulations, a total of 1,152 slams were generated over 5 hours and 38 minutes of simulated sea time. Whilst this is a relatively short 
amount of sea time to extrapolate long term slam load statistics it is sufficient to demonstrate the methodology.

\begin{tabular}{|c|c|c|c|c|c|c|c|c|}
\hline & \multicolumn{9}{|c|}{ Modal period (s) } \\
\hline Significant wave height (m) & 3 & 4 & 5 & 6 & 7 & 8 & 9 & 10 \\
\hline 0.5 & & & & & & & & \\
\hline 1 & & & & & & & & \\
\hline 1.5 & & & & & & 0.037 & 0.216 & 0.162 \\
\hline 2 & & & & & 0.019 & 0.097 & & \\
\hline 2.5 & & & 0.046 & 0.041 & 0.207 & 0.431 & & \\
\hline 3 & & & & & 0.568 & 0.858 & 0.530 & \\
\hline 3.5 & & & & & 0.797 & 0.820 & 0.535 & \\
\hline 4 & & & & & & 0.826 & 0.757 & 0.680 \\
\hline
\end{tabular}

Table 6: Predicted normalized slam rate (slam rate $\mathrm{x}$ hull length/hull speed) for each wave height and modal period. Note that the rates shown are computed for head sea conditions at 38 knots with no active ride controls.

Table 6 shows the computed slam occurrence rate for each condition. Slamming is first identified at a wave height of $2.5 \mathrm{~m}$ for a modal period of 5 seconds. Slam occurrence rates then increase and slams occur over a wider range of wave heights as the modal period increases. The slam rates for 7 and 9s modal period conditions for significant wave heights between $2 \mathrm{~m}$ and $4 \mathrm{~m}$ are all less than the corresponding occurrence rate for $8 \mathrm{~s}$, the modal period for which peak motions were observed during model testing. As noted previously, the occurrence rates from the simulation are slightly higher than observed in the model test program. It should be noted that while these results give a broad indication of how slam rates are affected by wave height and modal period, they have been computed only for head seas and without ride active controls. Therefore they are considered to be significantly greater than during actual operations where there is the option to mitigate slamming by altering course, reducing speed and operating ride controls to reduce vessel motions. Further, whilst Table 6 includes all detected slam occurrences, a considerable number of the slam events identified are very small.

A normalized histogram of the relative vertical velocities in the slam simulations is shown in Figure 27 and is compared with the normalized distribution of slam velocities measured during the 
experimental tests. Whilst different sea conditions than those tested at model scale were simulated in this case study, some being more or less severe, all conditions contained in the experimental test set fitted within the envelope of the conditions shown in Table 6 and therefore the distributions of velocities in Figure 27 should be similar. It can be seen that the simulation does contain more slams with a relative vertical velocity greater than $2 \mathrm{~m} / \mathrm{s}$ compared with those experimentally measured, and conversely it lacks slams with a negative relative vertical velocity. In the simulation, no slam was recorded with a velocity less than $-2 \mathrm{~m} / \mathrm{s}$, compared with a relatively small $4 \%$ of the experimentally measured slams.

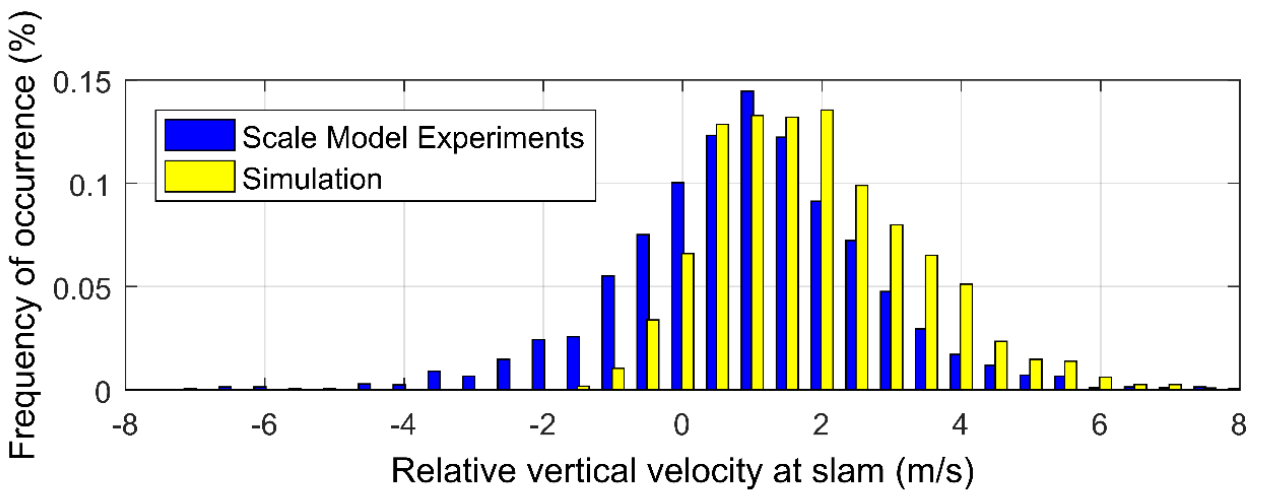

Figure 27: Normalised histogram of relative vertical velocities used to predict slam loading.

The slam load probability density functions for each condition were weighted according to the expected the percentage of the various sea conditions as given in Table 5 and then summed to yield a single overall slam load probability for head seas. Computed slam loads for each condition are weighted and combined to produce probability density and cumulative distribution functions of the slam load as shown in Figures 28 and 29 respectively. Slam load magnitudes are shown as multiples of total displacement (i.e. total hull weight). It can be seen from Figure 28 that the large majority of slams were about $25 \%$ of the hull weight and that only $3 \%$ of the slams exceeded the hull weight. However, whilst some extreme slams were predicted as shown in Figure 28, it should be borne in mind that the prediction method is based on very limited data for the extreme load, low probability cases and so these extreme load predictions are subject to considerable uncertainty. 
Indeed, this aspect is common to many problems involving statistical predictions where there is very little definitive data to support extrapolation to extreme value, low probability events.

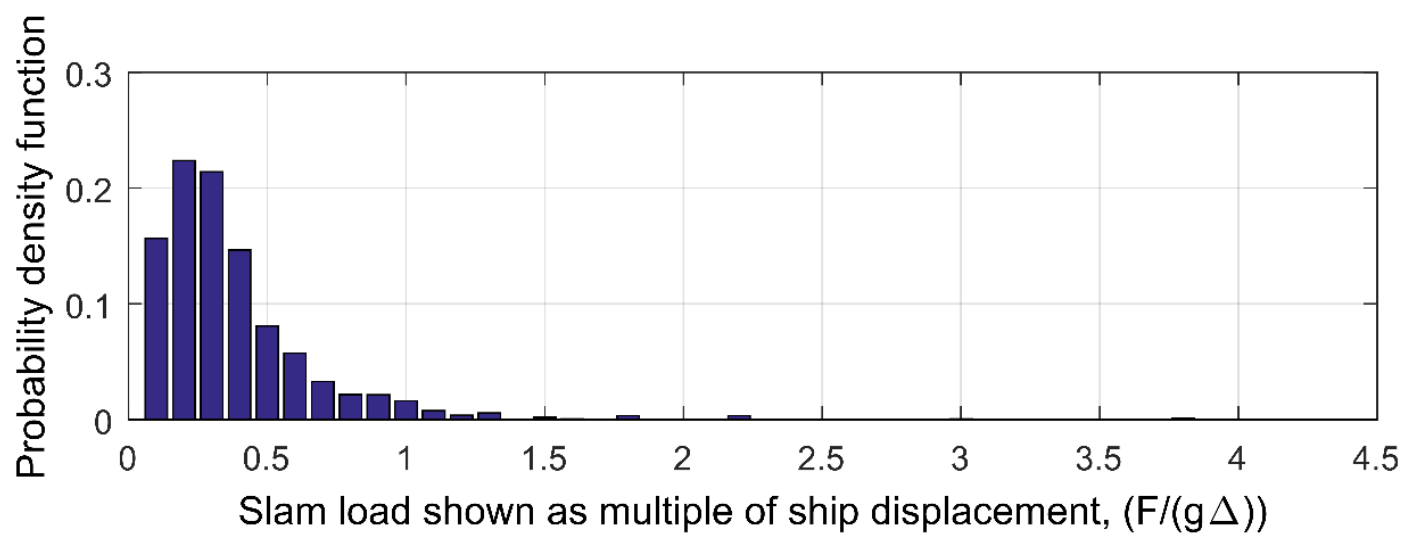

Figure 28: Probability density distribution function for centre bow slam loads from the timedomain seakeeping code for head seas at 38 knots without ride controls. The slam load is shown as a multiple of total ship displacement $(F /(g \Delta))$.

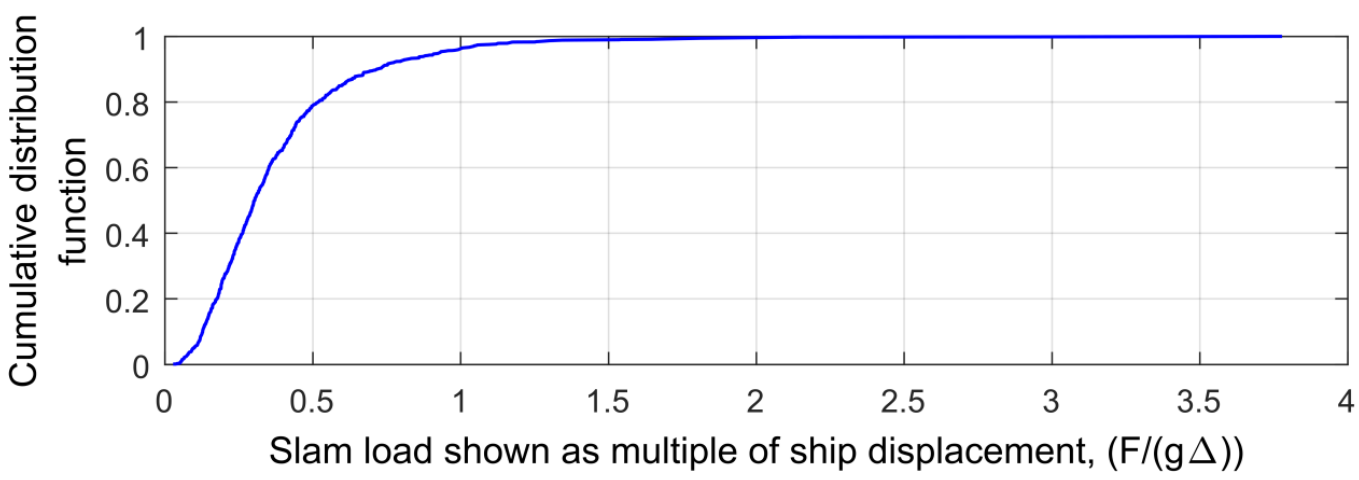

Figure 29: Cumulative probability distribution function for centre bow slam loads from the time-domain seakeeping code for head seas at 38 knots without ride controls. The slam load is shown as multiples of total ship displacement $(F /(g \Delta))$.

\section{Conclusions}

Random head sea tank tests on a hydro-elastic $2.5 \mathrm{~m}$ WPC facilitated the development of a data base for slam occurrence and severity. Slams were due to wave impact on the arch tops between the demi hulls and short center bow and the sharp rise of pressure when the arch section filled was used to identify the occurrence of slams. The distribution of peak slam pressure showed that slam 
loading is concentrated close to the aft end of the short center bow, this being consistent with previous investigations in regular seas. Slams occurred when the centre bow was close to its maximum downward movement in the encountered waves and occurred at intervals of about 3 to 4 encountered modal wave periods for periods of 8.5-10 seconds at full scale in larger seas but at longer intervals in smaller seas and for shorter modal periods. Slams were only detected in wave heights exceeding $1.5 \mathrm{~m}$ full scale equivalent. Slams events were found to commence and generally conclude before the immersion at the centre bow truncation reference point reached the maximum arch height. This observation supports the use of a 2D filling height criterion for slam occurrence. The model tests showed slam loads up to $132 \%$ of the hull weight but with median values around $25 \%$ of the hull weight. Slam induced bending loads in the forward section of the main hulls were found to reach $11.3 \%$ of the product of hull weight and length in sag with a very much smaller median of $2.5 \%$ of that product and generally similar values in hog following the initial sag moment due to the slam. At the aft section the maximum hog values were about twice the initial sag value. Slam durations were generally about 0.35 seconds full scale equivalent and rise times of the slam load were typically about half of the duration. The slam loading was thus found to take place on a similar time scale to the whipping period of the hull, and these results all show that hydro-elastic representation at model scale is essential to model testing for slamming behaviour. The greatest observed relative bow motion was approximately $5.4 \mathrm{~m}$ during a slam event and the median displacement for all slams was about $2.7 \mathrm{~m}$. The maximum observed relative vertical velocity of the bow to the water surface was close to the forward speed of the vessel with a median about half that value.

Simulation of slamming based on the experimental model test observations within the time domain seakeeping computation showed slightly higher median relative velocities at the slam instant than was observed in the model tests but had a similar range of variability. As a consequence, the seakeeping simulation yielded slightly higher median loads dud to slamming. 
The slam force showed greatest correlation with the relative vertical velocity at the instant of slamming and so this velocity was applied to the prediction of slam force.

When applied in the time domain computational simulation of slamming in head seas representative of a typical operating route at full scale at 38 knots but with no ride control system slamming was only predicted in seas greater than $1.5 \mathrm{~m}$ significant wave height and most frequently for a modal wave period of 8 seconds. The majority of slams loads were predicted to be about $25 \%$ of the hull weight, but as the experimental tests showed the largest slams were much larger than this at about $132 \%$ of hull weight. However, whilst the computational simulation predicted even larger slam loads, there is inevitable uncertainty regarding the most severe slams which can occur as this would require extremely long tank testing and associated refinement of the method of predicting the largest slams in the extreme value, low probability range.

The time-domain seakeeping program would be a useful tool for ship design as it is computationally far less intensive than a three-dimensional finite element or computational fluid dynamics model. Where an FE or CFD model can only economically consider very few slams, the advantage of the empirical model lies in the ability to analyse a large sample of slams, giving the ability to statistically forecast extreme slam events. However, the empirical slam model developed here could be improved by more extensive model testing to better identify the probability of extreme slam event loadings. Also, whilst a clear linear trend was found between the centre bow slam load and vertical bending moments at the forward links but not at the aft links, a fuller investigation of the transmission of slam induced bending along the hull length is needed. Finally, it should be noted that whilst the most severe slamming occurs in head seas as investigated here, there is a need to investigate the occurrence and severity of slamming in oblique sea conditions as well as the potential of ride control systems for slam mitigation (Shahraki et al., 2016).

\section{Acknowledgements.}

This investigation has been supported by INCAT Tasmania, Revolution Design, the Australian Research Council and the University of Tasmania. 
Davis, M. R., and Holloway, D. S. The influence of hull form on the motions of high speed vessels in head seas. Ocean Engineering, 30, 2091-2115, 2003.

Davis, M. R., Watson, N. L. and Holloway, D. S. Measurements of response amplitude operators for an $86 \mathrm{~m}$ high speed catamaran, Journal of Ship Research, 49(2), 121-143, 2005.

Dessi, D., Mariani, R., La Gala, F., and Benedetti, L. Experimental analysis of the wave-induced response of a fast monohull via a segmented-hull model. Proceedings of the 7th International Conference on Fast Sea Transportation FAST 03, vol. 2, 75-82, 2003.

Dessi, D., Mariani, R. and Coppottelli, G., Experimental investigation of the bending vibration of a fast vessel, Australian Journal of Mechanical Engineering, 4(2), 125-144, 2007.

French, B. J., Thomas, G.A., Davis, M.R, Holloway, D.S., and Mason, L. Time-domain simulations of wet deck slamming - a hybrid theoretical and empirical approach. Proceedings of Seventh International Conference on HighPerformance Marine Vehicles HIPER 10, Melbourne, Florida, 123-134, 2010.

French, B. J,. Thomas, G.A., Davis, M.R. and Holloway D.S., A high Froude number time-domain strip theory for ship motion predictions in irregular waves, Proceedings of the 18th Australasian Fluid Mechanics Conference: Hydrodynamics, Launceston, Tasmania, Australia, Section: Hydrodynamics, 1-4, 2012.

French, B.J., Thomas, G.A. and Davis, M.R., Slam characteristics of a high-speed WPC in irregular waves", International Journal of Maritime Engineering, 156 (A1), 25-36, 2014.

French, B.J., Thomas, G.A. and Davis, M.R., Slam occurrences and loads of a high-speed wave piercer catamaran in irregular seas", Proceedings of the Institution of Mechanical Engineers, Part M: Journal of Engineering for the Maritime Environment, 229(1), 45-57, 2015.

Hermundstad, O., Aarsnes, J., and Moan, T. Hydroelastic analysis of a high speed catamaran in regular and irregular waves. Proceedings of Fourth International Conference on Fast Sea Transportation FAST07, Sydney, 447-454, 2007. Holloway, D.S. and Davis, M.R., Green function solutions for the transient motion of water sections, Journal of Ship Research, 46(2), 99-120, 2002.

Holloway, D. S., and Davis, M. R. Ship motion computations using a high Froude number time domain strip theory. Journal of Ship Research 50(1), 15-30, 2006.

INCAT Tasmania. Website http://www.incat.com.au/, 2016.

Lavroff, J. and Davis, M.R., Slamming kinematics, impulse and energy transfer for wave-piercing catamarans, Journal of Ship Research, 59 (3), 145-161, 2015. 
Lavroff, J., Davis, M.R., Holloway, D.S.H. and Thomas, G.A., The whipping vibratory response of a hydroelastic segmented catamaran model. Proceedings of the 9th International Conference on Fast Sea Transportation FAST2007, Shanghai, 600-607, 2007.

Lavroff, J., Davis, M.R., Holloway, D.S. and Thomas, G.A., The Vibratory Response of High-Speed Catamarans to Slamming Investigated by Hydroelastic Segmented Model Experiments, International Journal of Maritime Engineering, 151, 1-11, 2009.

Lavroff, J., Davis, M.R., Holloway, D.S. and Thomas, G.A., Slamming of High-Speed Catamarans in Severe Sea Conditions Investigated by Hydroelastic Segmented Model Experiments, Proceedings of the Twenty Eighth Symposiumn on Naval Hydrodynamics, Pasadena, California, Section: Nonlinear wave induced motions and loads, 1-12, 2010.

Lavroff, J., Davis, M.R., Holloway, D.S. and Thomas, G.A., Determination of wave slamming loads on high-speed catamarans by hydroelastic segmented model experiments, International Journal of Maritime Engineering, 153(A3), 185-197, 2011.

Lavroff, J., Davis, M.R., Holloway, D.S. and Thomas, G.A., Wave slamming loads on wave-piercer catamarans operating at high-speed determined by hydro-elastic segmented model experiments, Marine Structures, 33 pp. 120 142. 2013.

Lloyd, A., Seakeeping: Ship Behaviour in Rough Weather. Ellis Horwood, 1989.

McTaggart, K., Datta, I., Stirling, A., Gibson, S. and Glen, I., Motions and loads of a hydroelastic frigate model in severe seas, Transactions of Society of Naval Architects and Marine Engineers, 105, 427-453, 1997.

McVicar, J.J., Lavroff, J., Davis, M.R. and Davidson, G. Transient slam load estimation by RANSE simulation and by dynamic modeling of a hydroelastic segmented model", Proceedings of the 30th Symposium on Naval Hydrodynamics, Hobart, Tasmania, Section: Nonlinear Wave Induced Motion and Loads 3, 1-16, 2014.

McVicar, J.J., Lavroff, J., Davis, M.R. and Thomas, G.A, Effect of slam force duration on the vibratory response of a lightweight high-speed wave-piercing catamaran, Journal of Ship Research, 59 (2), 69-84, 2015.

Okland, O., Zhao, R., and Moan, T. Numerical assessment of segmented test model approach for measurement of whipping responses. Proceedings of Fourth International Conference on Fast Sea Transportation FAST 03, vol. 2, 87-94, 2003.

Roberts, T. Route assessment for Higashi Nihon Line. Technical Report, Revolution Design, Hobart, Tasmania, 2005. Shahraki, J.R., Davis, M.R., Shabani, B., AlaviMehr, J.,Thomas, G.A., Lavroff, J. and Amin, W.A.I., Mitigation of slamming of large wave-piercing catamarans, Proceedings of the 30th Symposium on Naval Hydrodynamics, 2-7 November 2014, Hobart, Tasmania, Nonlinear Wave Induced Motion and Loads 2, 1-13, 2016. 